\title{
Design Optimization of the OC3 Phase IV Floating Spar-Buoy, Based on Global Limit States
}

\author{
Mareike Leimeister ${ }^{\mathrm{a}, \mathrm{b}, *}$, Athanasios Kolios ${ }^{\mathrm{a}}$, Maurizio Collu ${ }^{\mathrm{a}}$, Philipp Thomas ${ }^{\mathrm{b}}$ \\ a University of Strathclyde, Naval Architecture, Ocean and Marine Engineering, Glasgow G4 OLZ, United Kingdom \\ ${ }^{b}$ Fraunhofer IWES, Institute for Wind Energy Systems, Am Luneort 100, 27572 Bremerhaven, Germany
}

\begin{abstract}
Floating offshore wind turbine (FOWT) systems are a fast-evolving technology, however, still have to gain economic competitiveness to allow commercial market uptake. Design optimization, focusing on cost reduction while ensuring optimum system performance, plays a key role in achieving these goals. Hence, in this work, an approach for optimizing a floating concept, utilizing global limit states, is developed. The optimization is carried out in Python, linked with Modelica and Dymola for modeling and simulation. For the FOWT design, the over-dimensioned OC3 spar-buoy is utilized. This is modified during the optimization regarding its geometrical dimensions and ballasting. The optimization criteria stability, mean and dynamic displacements, and tower top acceleration are used for formulating the objective functions. The optimization is carried out for one design load case, which is most critical for the considered criteria. Based on an initial study, NSGAll is chosen as optimizer. The convergence of the optimization is examined and the optimum design solution selected. In post-processing analyses, the overall performance of the optimized FOWT system is approved. The presented approach shows one example for the design optimization of a FOWT system and should deal as basis for more advanced design optimization tasks, including local characteristics and reliability aspects.
\end{abstract}

Keywords: Design optimization, Floating platforms, Global limit states, Floating offshore wind turbines, Spar-buoy

\section{Introduction and Outline}

Floating support structures for offshore wind turbines are a convenient solution for deep water sites. However, higher costs, especially for the substructure, additional equipment (such as moorings and anchors), and installation challenge the market uptake of floating offshore wind technology [1]. First floating prototypes, for instance the Hywind spar floater, are highly over-dimensioned for safety reasons and due to the still low technology readi-

Abbreviations: ALPSO, Augmented Lagrangian Particle Swarm Optimization; COBYLA, Constrained Optimization BY Linear Approximation; DLC, Design Load Case; FOWT, Floating Offshore Wind Turbine; IEC, International Electrotechnical Commission; IWES, Institute for Wind Energy Systems; JONSWAP, JOint North Sea WAve Project; MDAO, Multi-disciplinary Design, Analysis, and Optimization; MOEA, Multi-Objective Evolutionary Algorithm; MoWiT, Modelica for Wind Turbines; NREL, National Renewable Energy Laboratory; NSGAll, Nondominated Sorting Genetic Algorithm II; NSGAIII, Non-dominated Sorting Genetic Algorithm III; OC3, Offshore Code Comparison Collaboration; OC4, Offshore Code Comparison Collaboration Continuation; PyGMO, Python parallel Global Multi-objective Optimizer; Rkfix4, Runge-Kutta fixed-step and 4th order method; SPEA2, Strength Pareto Evolutionary Algorithm 2; SWL, Still Water Level; TI, Turbulence Intensity.

* Corresponding author. Tel.: +49-471-14290-384. E-mail address: mareike.leimeister@iwes.fraunhofer.de 
ness level of and experience with FOWTs (floating offshore wind turbines). This, however, inhibits fast gain of economic competitiveness. Hence, design optimization of FOWTs with respect to their costs and performance is of high relevance to make them economically viable and to accelerate their market uptake.

Other studies show also the relevance of applying optimization approaches for the hydrodynamic response of [2-8] and loads on [5-7,9] floating systems, as well as for cost reduction of floating offshore wind turbines $[2-7,9]$. While a variety of optimization approaches is available in the literature for bottom-fixed offshore wind turbine systems, focusing on the optimization of either the bottom-fixed support structure [8,10-13], or the blades [14] and tower [11,14,15], or even an entire wind farm [16-21], the number of optimization approaches, dealing with the highly complex floating offshore wind turbine system, is very limited. While for bottom-fixed offshore wind turbine systems both optimization methodologies of analytical nature based on gradients [12,13] and evolutionary optimization approaches [15-18] can be found, for floating offshore wind turbine systems more typically genetic algorithm optimization approaches are applied [2-4,9]. However, especially because of the complexity of floating offshore wind turbine systems, which come with coupled motions, aero-hydro-servo-elastic dynamics, non-linear behavior, and additional components such as mooring lines, the optimization approaches presented in the literature are tailored to a specific optimization task. The implementation of the floating offshore wind turbine system is often simplified by using reduced-order models $[5,6,9,22]$ and even the fully-coupled dynamics, as mentioned above, are sometimes only partially modeled [7,8]. Thus, in [23,24], a modular framework for automated simulation and optimization is developed and presented. This framework utilizes the MoWiT (Modelica for Wind Turbines) library ${ }^{1}$, developed and continuously enhanced at Fraunhofer IWES (Institute for Wind Energy Systems) [25-28], for modeling the entire wind turbine system including the environmental conditions and representing the fully-coupled aero-hydro-servo-elastic dynamics. The modeling happens component-based, which brings high flexibility in modeling of any state-of-the-art onshore or offshore bottom-fixed or even floating wind turbine system. Coupling the MoWiT library to the Python-based programming environment allows automated execution of fully-coupled simulations, as well as solution of optimization problems of any kind, such as design optimization of the floating support structure, as covered in this work, or even the realization of a direct optimization approach, as presented in [29], or other optimization tasks as described in [24]. This high versatility of the modular Python-Modelica framework is even supplemented by the option of parallelized processing of simulation and/or optimization tasks. [24]

The study by [30], which was based on survey results, showed that - apart from the levelized cost of energy ease of maintenance and manufacturing, as well as system performance are most important criteria for FOWTs. Furthermore, an advanced spar-buoy floater design turned out to have the highest potential for a fast and successful market uptake. Hence, in this work, the floating offshore spar-buoy wind turbine system from phase IV of the OC3 (Offshore Code Comparison Collaboration) project [31] is used to apply a design optimization approach, utilizing the above mentioned Python-Modelica framework developed at Fraunhofer IWES [23,24]. The objectives of this design optimization are to reduce the degree of over-dimensioning of the spar-buoy floater, which benefits the overall system costs, as well as the manufacturability and handleability of the structure, but at the same time to maintain reasonable and safe global system performance even in critical environmental conditions. The presented design optimization approach is kept deliberately simple at the first stage, not including load analyses of the structure, so that it can be used afterwards as basis for well-founded development of more sophisticated optimization strategies and concepts which consider more detailed criteria, such as local limit states, structural integrity, as well as reliability aspects.

In this paper, first, the reference system to be analyzed and used for applying the developed optimization approach is presented in Chapter 2, covering the floating wind turbine system, the selected design variables, as well as the defined global limit states. Based on this, the formal declaration of the optimization problem, comprising the design variables, objective functions, and (in-)equalities constraints, is given in Chapter 3 . The optimization approach is then presented in Chapter 4, ranging from the design load cases used for simulations

\footnotetext{
${ }^{1}$ Formerly OneWind Modelica library
} 
and analyses, to the developed Python-Modelica framework for automated simulation and optimization, and in the end to the specific optimization settings. Afterwards in Chapter 5, the results of the optimization are analyzed and the selection procedure for determining the optimum spar-buoy design is outlined. Further evaluation of the optimization approach and results are covered in Chapter 6. Finally (Chapter 7), the paper closes with some conclusion.

\section{Description of the System Analyzed}

To deploy the design optimization approach, first, a reference framework has to be set up. This comprises the floating wind turbine system (Section 2.1), including the spar-buoy floater design which is about to be optimized, and the system variables which can be modified during the optimization process (Section 2.2). Furthermore, the global limit state criteria have to be selected (Section 2.3), on which basis the objective functions are then defined.

\subsection{Floating Wind Turbine System}

For the floating offshore wind turbine system, the Hywind-inspired spar-buoy concept from OC3 phase IV [31], visualized in Figure 1, is chosen, as a spar-buoy floating wind turbine system is expected to have the highest potential for fast commercialization [30] and, furthermore, the OC3 spar-buoy design is highly over-dimensioned. The spar-buoy floater consists of two cylindrical elements with one tapered part between them and is partially filled with ballast. The floating platform carries the upwind, three-bladed NREL (National Renewable Energy Laboratory) $5 \mathrm{MW}$ wind turbine [32] with an offshore adapted tower and modified control system. The entire floating system is moored to the seabed (at a water depth of $320 \mathrm{~m}$ ) by means of three evenly spaced catenary lines. Some main properties of this offshore wind turbine system are presented in Table 1. Elevations are given as distance above the still water level (SWL), while depths are specified as distance below SWL.

Table 1: Properties of the spar-buoy floating wind turbine system from OC3 phase IV [31,32].

\begin{tabular}{llr}
\hline Part & Parameter & Value \\
\hline Rotor-nacelle assembly & Rotor diameter & $126.0 \mathrm{~m}$ \\
& Hub height & $90.0 \mathrm{~m}$ \\
& Mass & $350,000 \mathrm{~kg}$ \\
& Cut-in, rated, cut-out wind speed & $3.0 \mathrm{~m} / \mathrm{s}, 11.4 \mathrm{~m} / \mathrm{s}, 25.0 \mathrm{~m} / \mathrm{s}$ \\
\hline Tower & Base, top elevation & $10.0 \mathrm{~m}, 87.6 \mathrm{~m}$ \\
& Top elevation, diameter, thickness & $87.6 \mathrm{~m}, 3.87 \mathrm{~m}, 0.019 \mathrm{~m}$ \\
& Base elevation, diameter, thickness & $10.0 \mathrm{~m}, 6.5 \mathrm{~m}, 0.027 \mathrm{~m}$ \\
& Mass & $249,718 \mathrm{~kg}$ \\
\hline Floater & Top elevation, diameter & $10.0 \mathrm{~m}, 6.5 \mathrm{~m}$ \\
& Depth range of taper & $4.0 \mathrm{~m} \mathrm{to} 12.0 \mathrm{~m}$ \\
& Base depth, diameter & $120.0 \mathrm{~m}, 9.4 \mathrm{~m}$ \\
& Mass (including ballast) & $7,466,330 \mathrm{~kg}$ \\
\hline Mooring system & Fairleads depth, radius from centerline & $70.0 \mathrm{~m}, 5.2 \mathrm{~m}$ \\
& Anchors depth, radius from centerline & $320.0 \mathrm{~m}, 853.87 \mathrm{~m}$ \\
& Mooring line length (unstretched), diameter & $902.2 \mathrm{~m}, 0.09 \mathrm{~m}$ \\
\hline
\end{tabular}




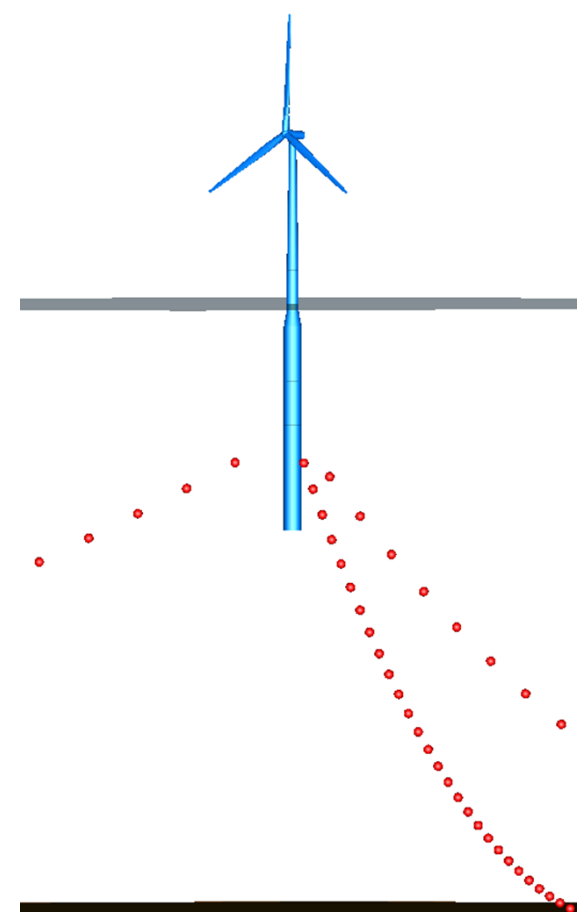

Figure 1: The OC3 spar-buoy FOWT system modeled in MoWiT and visualized in Dymola.

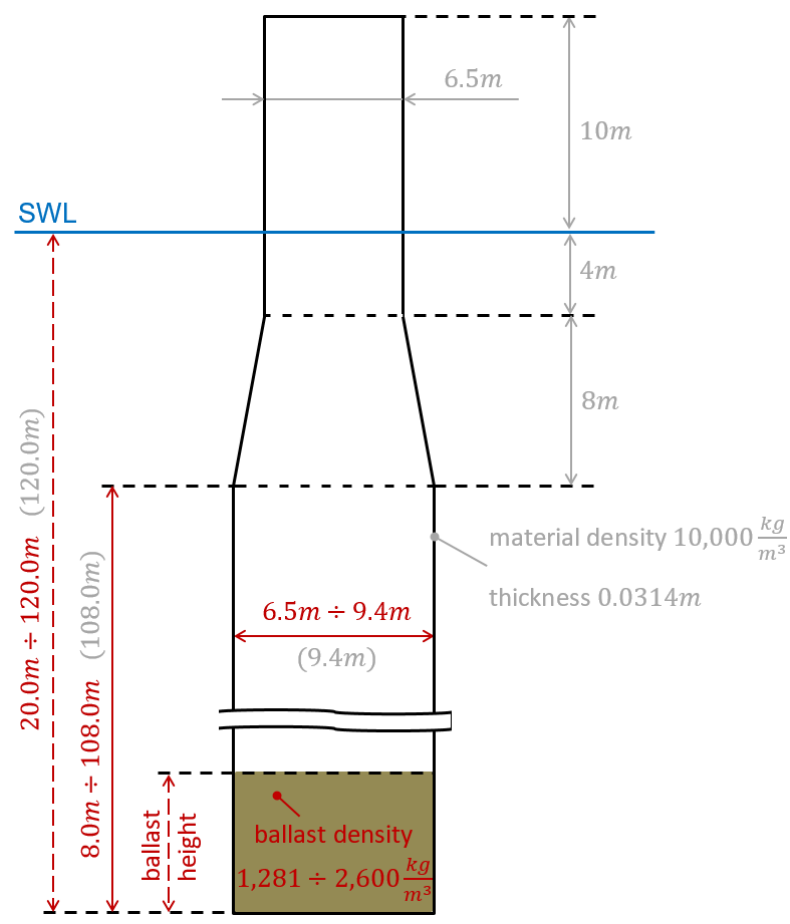

Figure 2: Fixed/original (grey, right/bracketed) and modifiable (red, left, dependent dashed) variables.

\subsection{Design Variables}

The purpose of this work is the design optimization of the floating wind turbine support structure, because this has a significantly larger contribution to the system costs compared to bottom fixed designs. Hence, the focus lies on the floating platform, meaning that wind turbine (tower and rotor-nacelle assembly), as well as the station-keeping system properties remain unchanged, while some of the floater system variables are free to be altered. In the following, these design variables, which are modifiable during the optimization, are defined.

\subsubsection{Geometric Design Variables}

Geometric system variables of the floater are diameters, thicknesses, and lengths of the floating structure. The top diameter and elevation should retain their original values to ensure that the floater top fits the tower base and the hub height remains the same. Furthermore, it is decided to keep the total length of the top cylindrical part, as well as the length of the taper fixed to avoid significantly changed effects due to the wave impact on the upper part of the structure. Thus, the top end of the bottom cylindrical part remains unchanged at $12 \mathrm{~m}$ below SWL. However, length and diameter of the bottom cylindrical part are chosen to be the two modifiable geometric design variables, as it is also intended to decrease the outer dimensions - and hence the material costs - while still fulfilling global limit state criteria without losing performance.

To apply the basic working principle of a common spar floater, as the OC3 spar-buoy concept is, and to allow utilization of the same supply chain and manufacturing process as used for the original design, other (more extraordinary) concepts of spar floaters, such as designs with a deep ballast tank connected with tendons to the floating structure, are not considered. Thus, the base diameter of the spar-buoy should not fall below the diameter of the upper cylindrical element of $6.5 \mathrm{~m}$, which thus defines the lower bound for the diameter of the bottom cylindrical part. The original diameter value is given in Table 1 with $9.4 \mathrm{~m}$. This is directly taken as the maximum tolerated value for the base diameter, as the overall goal is the reduction of the outer dimensions. To allow a reduction in the total length of the spar-buoy, the original height of the bottom cylindrical part $(108.0 \mathrm{~m})$ is again 
used as upper bound, while the minimum allowable value is set to $8.0 \mathrm{~m}$. This corresponds to a minimum draft of the floating system of $20.0 \mathrm{~m}$, which on the one hand allows higher survival sea states compared to the recommended initial estimate for the minimum draft $(15.0 \mathrm{~m})$ [33] and on the other hand does not fall below the draft of another floater type equivalent, the semi-submersible from OC4 (Offshore Code Comparison Collaboration Continuation) phase II [34]. Figure 2 sketches the fixed parameters and modifiable (specified and dependent) design variables of the spar-buoy, stating also their original values and defined allowable value ranges.

Finally, as (local) structural integrity checks are not yet performed at this stage, the wall thickness of the floater remains unchanged at its original value of $0.0314 \mathrm{~m}$, which was determined within a floater model verification process, done in a separate study [28]. Furthermore, the same stiffness provided by the mooring system is used throughout the optimization, as the mooring system design would require a separate in depth optimization approach, which is not yet included in this study. To overcome the problem of re-designing the mooring system properties for maintaining the resulting stiffness for each different draft of the floater and corresponding change in the fairlead position, in the modeling the original positions of fairleads and anchors, as well as the original mooring system properties are used and the maintained mooring stiffness is passed to the floating structure.

\subsubsection{Ballast Design Variables}

With changing the geometric variables stated in Subsection 2.2.1, the structural mass, as well as the displaced water volume and resulting buoyancy change as well. In order to maintain the hub height and thus the $10 \mathrm{~m}$ elevation of the floater top, but also to allow for a variable center of mass which influences the system performance and hence the global limit state criteria, which will be defined later on in Section 2.3, ballast amount and density are set to be modifiable, too.

The required ballast mass can be determined from the chosen geometric design variables and predefined system dimensions. For the ballast density range it is decided to make use of common and cheap materials, such as sand with a density range from around $1,281 \mathrm{~kg} / \mathrm{m}^{3}$ to $2,082 \mathrm{~kg} / \mathrm{m}^{3}$ depending on the water content [35], concrete with a density between $1,750 \mathrm{~kg} / \mathrm{m}^{3}$ and $2,400 \mathrm{~kg} / \mathrm{m}^{3}$ [36], or other rocks like sandstone with a density of $2,600 \mathrm{~kg} / \mathrm{m}^{3}$ [37]. Thus, the range for the modifiable ballast density is chosen to be between $1,281 \mathrm{~kg} / \mathrm{m}^{3}$ and $2,600 \mathrm{~kg} / \mathrm{m}^{3}$, assuming that every density value can be achieved through mixture of the above mentioned common and cheap ballast types with each other and/or with water. With the selected ballast density, the required ballast height can be calculated from the determined ballast mass needed, however, it also has to be ensured that the computed ballast height lies within $0 \mathrm{~m}$ and the length of the bottom cylindrical part. If this is not the case, the selected variable values have to be adjusted according to the following case distinction, which is directly incorporated when modeling the floater (Section 4.2):

- If the required ballast filling height exceeds the chosen length of the bottom cylindrical part, the entire bottom cylindrical part is filled, however, the ballast density is increased proportionately, as shown in Equation 1.

$$
\text { final ballast density }=\frac{\text { required ballast height }}{\text { bottom cylinder length }} \cdot \text { selected ballast density }
$$

- If mass needs to be removed from the system to make it floatable, meaning if the resulting ballast height is negative, the ballast filling height is set equal to zero and the floater structure material density is reduced respectively, as given in Equation 2.

$$
\text { modified material density }=\frac{(\text { structural weight based on selected dimensions })-(\text { excessive weight })}{\text { structure volume based on selected dimensions }}
$$

\subsection{Global Limit States}

The objectives for the optimization focus on the global system performance. Thus, the system rotational stability, translational displacements, and nacelle acceleration make up the global limit state criteria used for setting up the objective functions. Their descriptions and envisaged values are given hereinafter and summarized 
in Table 2. Due to the overall goal of reducing the degree of over-dimensioning of the floating support structure, common operational limits for the global system performance of a FOWT are directly used as the target values.

Table 2: Global limit state criteria for the design optimization.

\begin{tabular}{lcc}
\hline Criterion & Objective & Constraint \\
\hline Total inclination angle & $10.0^{\circ}$ & $\leq 10.0^{\circ}$ \\
Dynamic translational motion & minimized & $\geq 0.0 \mathrm{~m}$ \\
Horizontal nacelle acceleration & $0.2 \mathrm{~g} \approx 1.962 \mathrm{~m} / \mathrm{s}^{2}$ & $\leq 1.962 \mathrm{~m} / \mathrm{s}^{2}$ \\
\hline Mean translational motion & - & $\leq 64.0 \mathrm{~m}(=20 \%$ of $320.0 \mathrm{~m})$ \\
\hline
\end{tabular}

\subsubsection{System Rotational Stability}

The stability criterion of a FOWT system is represented by the maximum combined rotation angle, meaning the effective inclination angle (combined roll and pitch motion). Based on conventional values [38-40], the targeted total inclination is set equal to $10.0^{\circ}$, which must not be exceeded.

\subsubsection{Translational Motions}

Floating wind turbines will drift away from their initial position during operation due to wind and wave loading, however, some motion restrictions apply to FOWT systems. For example for wind turbines supported by tension leg platforms, the translational motion restrictions are quite stringent because of the tendons used for stationkeeping [41]. This is not applicable to the floating spar-buoy wind turbine as this is moored with catenary lines and there are no publically available specific limits for allowable translational displacements of a floating spartype wind turbine; however, for all FOWTs the allowable motion of the power cable is the key factor for restricting the translational displacement of the operating system.

There are two components of the total translational displacement (combined surge, sway, and heave motion) that need to be distinguished in the analyses: the static, meaning average, displacement, which is mainly due to the thrust on the wind turbine, and the dynamic displacement, representing the oscillatory motion due to turbulent wind loading and alternating wave loads. As there will always be a mean translational displacement, due to the thrust force, which is coupled to the power production mode of the wind turbine, it is not advisable to target a certain static displacement. Thus, the mean translational motion is not selected as optimization objective, but a constraint for the maximum static displacement is specified, following a rule of thumb, as $20 \%$ of the water depth $(320.0 \mathrm{~m})$, leading to $64.0 \mathrm{~m}$. The dynamic translational motion, however, is selected as optimization objective and aimed for being minimized to keep the oscillatory motion of the power cable as low as possible.

\subsubsection{Nacelle Acceleration}

For the wind turbines being placed on top of a floating platform the motions are most critical, especially the accelerations at the tower top. Due to the fact that the nacelle contains sensitive components - such as gearbox, generator, and bearings - its motion has to be restricted, as otherwise, when exceeding certain acceleration limits, the turbine has to stop operation. The common operational limit for the maximum allowable nacelle acceleration is $20 \%-30 \%$ of the gravitational acceleration $(\mathrm{g})[38,42,43]$, which corresponds to an acceleration of around $1.962 \mathrm{~m} / \mathrm{s}^{2}$ to $2.943 \mathrm{~m} / \mathrm{s}^{2}$. The final tolerated acceleration highly depends on the specific turbine. Thus, the more conservative value of $1.962 \mathrm{~m} / \mathrm{s}^{2}$ is used in this study as upper bound for the nacelle acceleration.

\section{Optimization Problem}

The optimization problem, meaning the optimization task, has to be defined. This comprises the declaration of design variables $\left(x_{i}\right)$, which are to be modified during the optimization process, (Section 3.1); objective functions 
$\left(f_{i}\right)$, which describe the targets of the optimization and are (depending on the optimization routine) mostly formulated in that way that the functions are to be minimized, (Section 3.2); and (in-)equalities constraints $\left(g_{i} \leq 0\right.$ and $h_{i}=0$, respectively) for optimization criteria and parameters, if they are only allowed to take on specific values or for instance the target value should be approached from only one side on the numerical scale, (Section 3.3). The general formulation of such an optimization problem with multiple objective functions can be written as

$\begin{array}{lll}\text { find } & X=\left\{x_{1}, \ldots, x_{k}\right\} & \\ \text { minimize } & f_{i}(X) & , i=1, \ldots, l \\ \text { subject to } & h_{i}(X)=0 & , i=1, \ldots, m \\ \text { subject to } & g_{i}(X) \leq 0 & , i=1, \ldots, n\end{array}$

The corresponding declarations are given in the following, based on the information and descriptions outlined in Chapter 2. Furthermore, a new external function system is introduced, as it is not possible to formulate objective functions and constraints directly as function of the design variables due to the complexity of the considered FOWT system. Thus, system $(X)$ means that the fully-coupled FOWT system with the specified design variables is evaluated externally (the tool is introduced in Section 4.2), to finally derive the parameters for the objective functions and constraints.

\subsection{Declaration of the Design Variables}

The three selected design variables of the OC3 spar-buoy floater are the base diameter, the height of the bottom cylindrical part, as well as the density of the ballast, as derived and described in detail in Section 2.2. Thus, the design variables vector $X=\left\{x_{1}, x_{2}, x_{3}\right\}$ contains the following three elements: $x_{1}$, the base diameter; $x_{2}$, the height of the bottom cylindrical part; and $x_{3}$, the ballast density.

\subsection{Declaration of the Objective Functions}

Three global limit states, as specified in Section 2.3, are used for setting up the objective functions. The optimization problem itself is multi-objective. Thus, the objective functions are formulated separately and not just in one single objective function. The three objective functions are: $f_{1}$ for the total inclination angle criterion; $f_{2}$ for the dynamic translational motion criterion; and $f_{3}$ for the horizontal nacelle acceleration criterion. The objective functions for inclination and acceleration criteria are both normalized with respect to their target values, while for the objective function for the dynamic translational motion no normalization is carried out. Thus, the formal description of the three objective functions is expressed in Equations 3 to 5 .

$$
\begin{aligned}
f_{1}(\operatorname{system}(X)) & =\frac{\mid \text { total inclination angle }-10.0^{\circ} \mid}{10.0^{\circ}} \\
f_{2}(\operatorname{system}(X)) & =\text { dynamic translational motion } \\
f_{3}(\operatorname{system}(X)) & =\frac{\mid \text { horizontal nacelle acceleration }-1.962 \mathrm{~m} / \mathrm{s}^{2} \mid}{1.962 \mathrm{~m} / \mathrm{s}^{2}}
\end{aligned}
$$

\subsection{Declaration of the (In-)Equalities Constraints}

Both the design variables and the global limit state criteria are constrained, as stated in Sections 2.2 and 2.3, respectively. For each design variable a lower and upper bound is set, which limits the design space investigated. Furthermore, each criterion, used for defining the objective functions, is constrained from one side as well, and one more additional parameter, namely the mean translational motion, is bounded from one side. As all these constraints follow inequalities, there are in total ten inequalities constraints and no equality constraint. The assignment of the inequalities constraints is the following: $g_{1}$ and $g_{2}$ for $x_{1} ; g_{3}$ and $g_{4}$ for $x_{2} ; g_{5}$ and $g_{6}$ for $x_{3} ; g_{7}$ for the total inclination angle; $g_{8}$ for the dynamic translational motion; $g_{9}$ for the horizontal nacelle acceleration; 
and $g_{10}$ for the mean translational motion. The specific formulations of these inequalities constraints are given in Equations 6 to 15.

$$
\begin{array}{ll}
g_{1}\left(x_{1}\right) & =6.5 \mathrm{~m}-x_{1} \\
g_{2}\left(x_{1}\right) & =x_{1}-9.4 \mathrm{~m} \\
g_{3}\left(x_{2}\right) & =8.0 \mathrm{~m}-x_{2} \\
g_{4}\left(x_{2}\right) & =x_{2}-108.0 \mathrm{~m} \\
g_{5}\left(x_{3}\right) & =1,281 \mathrm{~kg} / \mathrm{m}^{3}-x_{3} \\
g_{6}\left(x_{3}\right) & =x_{3}-2,600 \mathrm{~kg} / \mathrm{m}^{3} \\
g_{7}(\operatorname{system}(X)) & =\text { total inclination angle }-10.0^{\circ} \\
g_{8}(\operatorname{system}(X)) & =- \text { dynamic translational motion } \\
g_{9}(\operatorname{system}(X)) & =\text { horizontal nacelle acceleration }-1.962 \mathrm{~m} / \mathrm{s}^{2} \\
g_{10}(\operatorname{system}(X)) & =\text { mean translational motion }-64.0 \mathrm{~m}
\end{array}
$$

\section{Optimization Approach}

The design optimization approach requires a FOWT system model, which is simulated and evaluated for a certain environmental condition. Thus, first (Section 4.1), design load cases (DLCs) which are proposed by standards are analyzed and a most critical DLC is worked out, which represents the environmental condition considered within the optimization simulations. The automated execution of the DLCs, as well as the iterative optimization procedure are both comprised by the Python-Modelica framework, developed at Fraunhofer IWES. This framework is in detail described in $[23,24]$ and briefly introduced in Section 4.2. Afterwards (Section 4.3), the specific settings, used for the optimization of the OC3 spar-buoy floating wind turbine system, are defined.

\subsection{Design Load Cases}

In order to analyze the wind turbine system performance and to evaluate the critical parameters, selected in Section 2.3 as global limit states for setting up the objective functions, as specified in Section 3.2, at least the DLCs defined in the IEC (International Electrotechnical Commission) standard 61400-3 [44] have to be considered in general. However, as not every DLC is relevant for the particular global limit state criteria, commonly, specific critical load cases and environmental conditions are selected and used for the subsequent analyses [38,41,43,45-47]. Furthermore, in light of the computational effort and time that it would take when simulating several DLCs in each loop of the optimization process, in this study, it is decided to use only one critical DLC within the optimization. The choice of this most critical DLC is based on the following approach:

1. All DLCs given in IEC 61400-3 [44, p. 36-38] are evaluated and an initial selection of the most relevant DLCs with respect to the specified optimization objectives is made.

2. These pre-screened DLCs are simulated with the reference floating wind turbine system presented in Section 2.1. The simulations are performed in Dymola, based on the system model in Fraunhofer's MoWiT library and utilizing the Python-Modelica framework for automated simulation, which will be introduced in more detail in Section 4.2.

3. All simulated DLCs are evaluated regarding the selected objective functions. Based on this, the DLC(s) yielding the most critical results, meaning the highest values for the specified optimization objectives, are determined.

4. If all optimization criteria are most critical in one and the same DLC, this load case can directly be taken for the optimization. However, if different DLCs yield the most critical global limit state criteria, an appropriate DLC, combining all these worst load case conditions, is defined and used for the optimization. 
5. This means that only one DLC is used in the optimization process; however, to validate the suitability and representative nature of the chosen critical DLC, all DLCs, based on the initial selection done in 1., are simulated again for the final optimized floating wind turbine system design. This way it can be checked if the load case conditions, yielding the most critical optimization criteria for the original design, have switched to another DLC for the optimized system. If this was the case, the DLC selected for the use during the optimization procedure would have to be modified according to the new findings and the optimization and subsequent validation would have to be performed once again.

Based on the optimization objectives, defined in Section 2.3, the pre-screening of the large number of DLCs, recommended in the international standard IEC 61400-3 [44], is done. At first and even though wind turbine foundation designs are often governed by fatigue, all DLCs defined for fatigue analyses are directly excluded, as the optimization objectives focus on global extreme system behavior without considering structural loads and integrity. From the remaining DLCs for ultimate loads, three operational design conditions are selected as design-relevant load cases with regards to the specified optimization objectives [29]:

- DLC 1.1 at three different wind speeds $(10.0 \mathrm{~m} / \mathrm{s}, 11.4 \mathrm{~m} / \mathrm{s}$, and $13.0 \mathrm{~m} / \mathrm{s})$ slightly below, at, and slightly above rated wind speed of the NREL $5 \mathrm{MW}$ wind turbine.

- The DLC 1.1 uses normal environmental conditions, hence, normal turbulent wind model, as well as normal irregular sea state and normal current model. The wind turbine is in normal power production.

- Around rated wind speeds, the highest thrust force is experienced by a wind turbine in operation. This loading is correlated to the platform inclination as response to the resulting overturning moment, as well as to a mean translational displacement of the floating system.

- Hence, DLC 1.1 at the mentioned three wind speeds is expected to yield critical total inclination angles of the floating system, as well as critical values for the mean translational motion, which, however, is not a direct optimization objective, but is constrained.

- DLC 1.3 at three different wind speeds $(8.0 \mathrm{~m} / \mathrm{s}, 11.4 \mathrm{~m} / \mathrm{s}$, and $25.0 \mathrm{~m} / \mathrm{s})$ below and at rated wind speed, as well as at the maximum operating wind speed (cut-out) of the NREL $5 \mathrm{MW}$ wind turbine.

- The DLC 1.3 uses an extreme turbulent wind model, while the irregular sea state and current model are considered to be normal. The wind turbine is in normal power production.

- This DLC represents critical conditions for a wind turbine at a wind-dominated location. The extreme turbulences in the wind speed time series contain high fluctuations, which excite the floating wind turbine system in oscillatory motions.

- Hence, if the wind turbine is wind-sensitive, DLC 1.3 is expected to yield critical values for the nacelle acceleration, as well as for the dynamic translational motion.

- DLC 1.6a at three different wind speeds $(8.0 \mathrm{~m} / \mathrm{s}, 11.4 \mathrm{~m} / \mathrm{s}$, and $25.0 \mathrm{~m} / \mathrm{s})$ below and at rated wind speed, as well as at the maximum operating wind speed (cut-out) of the NREL $5 \mathrm{MW}$ wind turbine.

- The DLC 1.6a considers, opposite to DLC 1.3, a severe irregular sea state, while normal current and turbulent wind models are used. The wind turbine is in normal power production.

- This DLC represents critical conditions for a wind turbine at a wave-dominated location. The severe irregular sea state comes with high fluctuations in the wave elevation time series, which excite the floating wind turbine system in oscillatory motions.

- Hence, if the wind turbine is wave-sensitive, DLC 1.6a is expected to yield critical values for the nacelle acceleration, as well as for the dynamic translational motion. 


\subsection{Python-Modelica Framework}

Fraunhofer IWES has developed the MoWiT library for fully-coupled aero-hydro-servo-elastic simulation of any wind turbine system. The modeling language utilized is Modelica ${ }^{2}$, which is object-oriented and equation-based. By means of the hierarchical structure within Modelica, the highly complex wind turbine system is modeled by means of six interconnected main components - the rotor, nacelle, operating control, support structure, wind, and waves -, which are again subdivided into further subcomponents. The full capabilities of the MoWiT library are described in [25-27], however, this library is constantly further enhanced and extended. The OC3 spar-buoy FOWT system, used in this work for the design optimization, has been implemented in MoWiT and verified in a separate study [28]. The simulation engine for executing simulations with this FOWT system model is Dymola ${ }^{3}$. A visualization of the modeled OC3 spar-buoy wind turbine is presented in Figure 1.

The programming framework for performing automated simulations and optimization tasks is based on the programming language Python ${ }^{4}$. One essential task of the Python programming framework is to establish the interface between the modeling environment (MoWiT) and the simulation engine (Dymola). This linkage is shown in Figure 3, which also points out the main parts within the Python-Modelica framework:

1. The specific wind turbine system model (modeled in MoWiT and to be simulated in Dymola) is processed by redefining variable values and setting simulation parameters.

2. Several processed models can be collated. Their corresponding simulations is managed by specifying either parallel or successive simulation execution and setting the number of useable processors (in case of batch calculations).

3. The defined simulations are performed with the provided models. The simulation results can further be post-processed based on additional code (e.g. as done for the optimization) and results files can be written.

4. These results files and of course the simulated models are the output of the Python-Modelica framework execution.

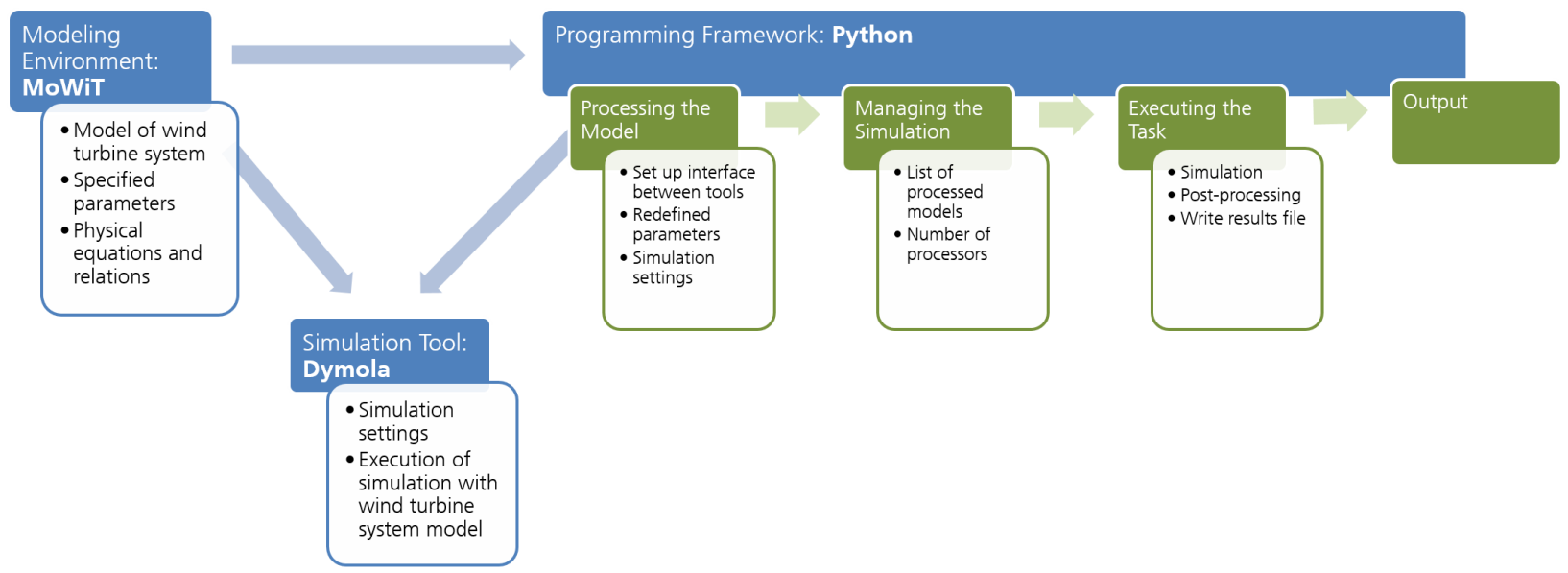

Figure 3: Python-Modelica framework for automated simulation, adapted from [24].

\footnotetext{
2 https://www.modelica.org/ (Accessed: 20 March 2019)

3 https://www.dymola.com/ (Accessed: 20 March 2019)

${ }^{4}$ https://www.python.org/ (Accessed: 20 March 2019)
} 
The collation of processed models, as well as the execution of several simulations in parallel, as mentioned in step 2, are of high relevance for the application for optimization tasks and DLC simulations. For automated execution of the large number of DLC simulations, additional scripts are written in Python for defining the different DLCs. On this basis the individual settings for all simulations within one DLC, such as the wind speed, wave height and period, and flow angles, are derived automatically. For more detailed information on the realization of DLC simulations by means of the above presented Python-Modelica framework, the reader is referred to [24].

\subsection{Optimization Settings}

In step 3 of the Python-Modelica framework, additional code is incorporated for extending the simulation framework for optimization tasks. Hence, first, the optimization problem and optimizer are defined and then the optimization algorithm, implying the simulation of the specified wind turbine system model with redefined design variables, is executed. For more details on the extension of the Python-Modelica framework for automated optimization, the reader is referred to $[23,24]$.

\subsubsection{Optimizer and Optimization Problem}

For the application of optimization tasks in a Python environment, there are a large number of optimizers available (open-source), such as

- OpenMDAO 5 for multi-disciplinary design, analysis, and optimization (MDAO);

- PyGMO ${ }^{6}$ the Python parallel global multi-objective optimizer;

- Platypus ${ }^{7}$ providing multi-objective evolutionary algorithms (MOEAs).

An overview of various optimizers and their classification and functionalities is given in [24]. From these, a few optimizers - namely ALPSO (Augmented Lagrangian Particle Swarm Optimization), COBYLA (Constrained Optimization BY Linear Approximation), NSGAII (Non-dominated Sorting Genetic Algorithm II), NSGAIII (Nondominated Sorting Genetic Algorithm III), and SPEA2 (Strength Pareto Evolutionary Algorithm 2) -, which are all gradient-free, are implemented in the Python-Modelica framework and tested. Due to the complexity of a wind turbine system, gradient-based optimizers cannot be utilized.

Furthermore, the optimization problem, as described in Chapter 3, comes with three design variables and corresponding lower and upper bounds (corresponding to six inequalities constraints), three objective functions, as well as four inequalities constraints. Thus, for the specific optimization task and application covered in this study, the optimizer should be capable of processing multi-objective problems. Hence, the three multi-objective optimizers NSGAII, NSGAIII, and SPEA2 from Platypus, which were already utilized in [18], are tested within this study in more detail on the specific optimization problem and it turned out that SPEA2 is converging very slow, while both SPEA2 and NSGAIII have a lower compliance rate of the defined constraints compared to NSGAII. Thus, NSGAll is selected to be used as optimizer within the design optimization of the OC3 spar-buoy FOWT system. Table 3 summarizes the pros and cons of the considered and compared optimizers.

NSGAll is a genetic algorithm, which obeys the principle of Darwin's theory of evolution. Hence, for such an optimizer, further parameters need to be specified: the population size and number of generations. The role of these two parameters is explained in the next Paragraph 4.3.2, covering the optimization algorithm. Within this study, the following values are chosen:

- For the population size, 36 individuals are used within each generation. This number is based on the available number of cores, so that all simulations within one generation can be executed in parallel at the same time.

\footnotetext{
5 http://openmdao.org/ (Accessed: 20 March 2019)

6 https://esa.github.io/pygmo/index.html (Accessed: 20 March 2019)

7 https://platypus.readthedocs.io/en/latest/ (Accessed: 20 March 2019)
} 
Table 3: Considered optimizers in comparison*.

\begin{tabular}{lcccc}
\hline Optimizer & Gradient-free & Multi-objective & Compliance with constraints & Convergence rate \\
\hline ALPSO & $\checkmark$ & $x$ & & \\
COBYLA & $\checkmark$ & $x$ & + & ++ \\
\hline NSGAII & $\checkmark$ & $\checkmark$ & 0 & + \\
NSGAIII & $\checkmark$ & $\checkmark$ & 0 & - \\
SPEA2 & $\checkmark$ & $\checkmark$ & & \\
\hline
\end{tabular}

* Optimizer has $(\mathcal{})$ or has not $(\boldsymbol{X})$ the feature; optimizer performs very good $(++)$, good $(+)$, neutral $(0)$, or bad (-).

- Based on the definition of the NSGAll optimizer from Platypus, the total number of simulations is required as input instead of the number of generations. The number of generations used within the optimization algorithm needs to be high enough to allow for convergence of the optimization. One option to determine the appropriate number of generations is by means of a sensitivity study. In this work, however, a more direct approach is utilized, as information on the performance and convergence rate of NSGAll is already available from the initial optimizer tests on the specific optimization problem. Based on this, the total number of simulations is increased significantly above the expected point of convergence and selected to be 2,000, which would correspond to more than 55 full generations simulated. The convergence is finally approved in the analysis of the simulation results, covered in Subsection 5.3.1.

\subsubsection{Optimization Algorithm}

With the specified optimization problem and the selected optimizer and corresponding parameter settings, the optimization algorithm is executed. This is an iterative process, which runs until the stop criterion is reached. The stop criterion can be defined by means of a specified threshold for the difference between the objective functions at two consecutive generations and/or by limiting the number of iterations within the optimization. Based on the functionalities of the NSGAll optimizer from Platypus, in this application, the total number of simulations makes up the stop criterion. The following steps are then iterated:

0 . Choosing from the prescribed value ranges, the design variables are redefined for each individual in the start generation $(n=0)$.

1. The individual wind turbine system designs are simulated (in parallel), using the selected critical DLC as simulation case.

2. Based on the simulation results, the objective functions are evaluated by selecting the largest value for the global limit state criteria obtained within the time series (excluding a pre-simulation time of $200 \mathrm{~s}$ for avoiding transients) and the prescribed constraints are checked.

3. Based on the performance of each individual with respect to the optimization objectives and constraints, the design variables for the individuals of the next generation $(n+1)$ are specified, complying with the boundaries for the design variables values.

4. Steps 1 to 4 are repeated until the total number of simulations is reached.

In step 2, some error handling is incorporated in case of an unsuccessful simulation. Before evaluating the objective functions, first, the last entry within the time series is analyzed. If this time value is the specified simulation length, the simulation was successful and the results evaluation is done as described in step 2. However, if the time value is below the specified simulation length, the simulation failed. Thus, the corresponding design is imperfect and should be excluded from the further consideration. Hence, the objective functions are not evaluated, but undesirable values are set for the optimization criteria - meaning values which are beyond the valid value ranges. 


\section{Results}

Based on the descriptions of the reference system (Chapter 2), the optimization problem (Chapter 3), and the optimization approach (Chapter 4), first, the critical DLC is to be determined, covered in Section 5.1, which is later on used for the optimization. All simulations are performed on an Intel ${ }^{\circledR}$ Xeon ${ }^{\circledR}$ CPU E7-8850 @2.00 GHz with 64-bit system and 80 virtual processors. The results of the iterative optimization approach are presented in Section 5.2 and analyzed with respect to the optimized spar-buoy design in Section 5.3.

\subsection{Selection of the Critical DLC}

According to the approach, outlined in Section 4.1, and the performed pre-screening of the DLCs, 54 simulations (18 each selected DLC) are executed in Dymola with the original OC3 spar-buoy FOWT system, modeled in MoWiT. The specific settings and descriptions of these DLC simulation cases are summarized in Table 4. The naming convention DLCx_wW_sS_yY is used, with $x$ indicating the number of the DLC (11 for 1.1, 13 for 1.3 and $16 \mathrm{a}$ for $1.6 \mathrm{a})$, $\mathrm{W}$ being replaced by the considered mean wind speed, $S$ referring to the seed number for the random generation of the turbulent wind conditions, and $\mathrm{Y}$ specifying the yaw misalignment angle between wind direction and the perpendicular to the rotor plane. As for the irregular waves, the seed number for the random phase angle is derived directly from the seed number for the turbulent wind, namely according to $S+6$, this value does not appear in the naming convention.

Table 4: Environmental conditions and simulation settings for the pre-selected DLCs.

\begin{tabular}{|c|c|c|c|c|c|c|c|c|}
\hline \multirow{2}{*}{ DLC } & \multicolumn{4}{|c|}{ Wind conditions } & \multicolumn{4}{|c|}{ Sea conditions } \\
\hline & $\mathrm{W}[\mathrm{m} / \mathrm{s}]$ & Long. TI & S & $\mathrm{Y}\left[{ }^{\circ}\right]$ & $\boldsymbol{H}_{\mathrm{s}}$ & $T_{\mathrm{p}}$ & Wave seed & Current speed \\
\hline \multirow{3}{*}{1.1} & 10.0 & $18.34 \%$ & $1 \ldots 6$ & $-8,0,8$ & $1.74 \mathrm{~m}$ & $6.03 \mathrm{~s}$ & $7 \ldots 12$ & $0.074 \mathrm{~m} / \mathrm{s}$ \\
\hline & 11.4 & $17.38 \%$ & $7 \ldots 12$ & $-8,0,8$ & $1.99 \mathrm{~m}$ & $6.44 \mathrm{~s}$ & $13 \ldots 18$ & $0.084 \mathrm{~m} / \mathrm{s}$ \\
\hline & 13.0 & $16.53 \%$ & $13 \ldots 18$ & $-8,0,8$ & $2.30 \mathrm{~m}$ & $6.92 \mathrm{~s}$ & $19 \ldots 24$ & $0.096 \mathrm{~m} / \mathrm{s}$ \\
\hline \multirow{3}{*}{1.3} & 8.0 & $35.00 \%$ & $1 \ldots 6$ & $-8,0,8$ & $1.44 \mathrm{~m}$ & $5.48 \mathrm{~s}$ & $7 \ldots 12$ & $0.059 \mathrm{~m} / \mathrm{s}$ \\
\hline & 11.4 & $26.97 \%$ & $7 \ldots 12$ & $-8,0,8$ & $1.99 \mathrm{~m}$ & $6.44 \mathrm{~s}$ & $13 \ldots 18$ & $0.084 \mathrm{~m} / \mathrm{s}$ \\
\hline & 25.0 & $16.68 \%$ & $13 \ldots 18$ & $-8,0,8$ & $4.94 \mathrm{~m}$ & $10.14 \mathrm{~s}$ & $19 \ldots 24$ & $0.184 \mathrm{~m} / \mathrm{s}$ \\
\hline \multirow{3}{*}{$1.6 a$} & 8.0 & $20.30 \%$ & $1 \ldots 6$ & $-8,0,8$ & $10.37 \mathrm{~m}$ & $14.70 \mathrm{~s}$ & $7 \ldots 12$ & $0.059 \mathrm{~m} / \mathrm{s}$ \\
\hline & 11.4 & $17.38 \%$ & $7 \ldots 12$ & $-8,0,8$ & $10.37 \mathrm{~m}$ & $14.70 \mathrm{~s}$ & $13 \ldots 18$ & $0.084 \mathrm{~m} / \mathrm{s}$ \\
\hline & 25.0 & $13.64 \%$ & $13 \ldots 18$ & $-8,0,8$ & $10.37 \mathrm{~m}$ & $14.70 \mathrm{~s}$ & $19 \ldots 24$ & $0.184 \mathrm{~m} / \mathrm{s}$ \\
\hline
\end{tabular}

For the wind conditions, the Kaimal spectrum for turbulent wind, according to IEC standard 61400-1 [48], is used. With regard to the turbulence intensity (TI), the lateral and transverse Tls are 0.8 and 0.5 , respectively, of the specified longitudinal TI. For each wind speed, three different yaw misalignment angles are considered, as well as six seeds. These are combined in such a way, that the first two seeds go with the first yaw angle, the third and fourth seed go with the second yaw angle, and the last two seeds go with the third yaw angle, leading to the following six ending terms of the simulation cases for DLC11_w10_: s1_y-8, s2_y-8, s3_y0, s4_y0, s5_y8, and s6_y8.

For the sea conditions, the JONSWAP (Joint North Sea Wave Project) wave spectrum is utilized. The significant wave height $\left(H_{\mathrm{s}}\right)$ is determined depending on the wind speed $(\mathrm{W})$, according to Equation 16 [49]. For DLC $1.6 \mathrm{a}$, which considers a severe irregular sea state, however, the 10 minutes average wind speed with recurrence period of 50 years from the turbulent extreme wind speed model is used for $W$ in Equation 16, based on the recommendation given in [44] to use the 50-year extreme significant wave height to be on the conservative side. According to [48], the value for the 10 minutes average turbulent extreme wind speed with recurrence period of 50 years equals the reference wind speed average over ten minutes for the IEC wind turbine class I, which amounts to $50 \mathrm{~m} / \mathrm{s}$. 


$$
H_{\mathrm{s}}=H_{0}\left(1+2.6 \frac{\left(\frac{\mathrm{W}}{V_{0}}\right)^{3}}{1+\left(\frac{\mathrm{W}}{V_{0}}\right)^{2}}\right) \quad ; H_{0}=1 \mathrm{~m}, \quad V_{0}=13 \mathrm{~m} / \mathrm{s}
$$

The common relation between the significant wave height and the peak period $\left(T_{\mathrm{p}}\right)$ is given in Equation 17 , based on [44].

$$
11.1 \sqrt{\frac{H_{\mathrm{s}}}{g}} \leq T_{\mathrm{p}} \leq 14.3 \sqrt{\frac{H_{\mathrm{s}}}{g}}
$$

The peak-shape parameter $(\gamma)$ of the JONSWAP wave spectrum depends on the relation of peak period and significant wave height, as expressed in Equation 18 [44].

$$
\gamma= \begin{cases}5 & \text { for } \frac{T_{\mathrm{p}}}{\sqrt{H_{\mathrm{s}}}} \leq 3.6 \\ \exp \left(5.75-1.15 \frac{T_{\mathrm{p}}}{\sqrt{H_{\mathrm{s}}}}\right) & \text { for } 3.6 \leq \frac{T_{\mathrm{p}}}{\sqrt{H_{\mathrm{s}}}} \leq 5 \\ 1 & \text { for } \frac{T_{\mathrm{p}}}{\sqrt{H_{\mathrm{s}}}}>5\end{cases}
$$

Due to the fact that a Pierson-Moskowitz spectrum, having a peak-shape parameter of $\gamma=1$ would be most realistic for deep water conditions, the lowest possible value for the peak-shape parameter is tried to be obtained. Hence, the peak period is derived based on Equation 19, leading to a peak-shape parameter of $\gamma=1.65$ for all simulation cases. This way, also the highest possible value for the peak period is obtained, which is thus most critical for spar-buoy floating systems with respect to their system eigenfrequencies.

$$
T_{\mathrm{p}}=14.3 \sqrt{\frac{H_{\mathrm{s}}}{g}}
$$

Finally, for the currents, as all pre-selected DLCs use the normal current model, no sub-surface currents have to be considered [44]. Furthermore, no breaking wave surf induced currents are considered due to the large distance of the floater to any coastal breaking wave zone. Hence, only wind-generated near-surface currents are employed. This current speed $\left(U_{\mathrm{W}}\right)$ can be determined depending on the depth $(z \leq 0 \mathrm{~m})$ below the SWL by means of Equation 20 [44].

$$
U_{\mathrm{W}}(z)= \begin{cases}U_{\mathrm{W}}(0)\left(1+\frac{z}{20 m}\right) & \text { for }-20 m \leq z \leq 0 m \\ 0 & \text { for } z \leq-20 m\end{cases}
$$

The wind-generated current velocity at the sea surface $\left(U_{\mathrm{W}}(0)\right)$ is obtained from Equation 21, based on [44] and utilizing the power law for a normal wind profile [44] to derive the wind speed at $10 \mathrm{~m}$ above SWL from the wind speed at hub height of $90 \mathrm{~m}$.

$$
U_{\mathrm{W}}(0)=0.01 \mathrm{~W}\left(\frac{10 m}{90 m}\right)^{0.14}
$$

With these settings and definitions, all 54 DLC simulation cases are run for $600 \mathrm{~s}$, using the solver Rkfix4 (Runge-Kutta fixed-step and 4th order method) with a fixed integrator step-size of $0.01 \mathrm{~s}$, which is a suitable value to obtain conservative values for the global dynamic response of the floating wind turbine system. Each 18 simulations per defined DLC category are run in parallel, which took approximately three hours, leading to around nine hours in total for all 54 DLC simulations. The resulting time series of these simulations are evaluated just from $200 \mathrm{~s}$ on to exclude any transients at the beginning of the simulations. Thus, the maximum inclination (combined roll and pitch angle), the maximum horizontal acceleration at the tower top, the maximum amplitude of the dynamic translational motion (combined surge, sway, and heave displacement), as well as the maximum mean translational motion (even if this is not an optimization criterion) are selected for each DLC simulation case. The five highest values each with the corresponding DLC simulation cases are presented in Table 5. 
Table 5: The five most critical DLCs for each optimization criterion and the constrained mean translational motion.

\begin{tabular}{|c|c|c|c|}
\hline \multicolumn{2}{|c|}{ Total inclination angle } & \multicolumn{2}{|c|}{ Horizontal nacelle acceleration } \\
\hline DLC16a_w11_s11_y8 & $4.9^{\circ}$ & DLC16a_w25_s16_y0 & $2.351 \mathrm{~m} / \mathrm{s}^{2}$ \\
\hline DLC11_w13_s17_y8 & $4.7^{\circ}$ & DLC16a_w11_s11_y8 & $2.338 \mathrm{~m} / \mathrm{s}^{2}$ \\
\hline DLC11_w13_s14_y-8 & $4.6^{\circ}$ & DLC16a_w8_s6_y8 & $2.317 \mathrm{~m} / \mathrm{s}^{2}$ \\
\hline DLC16ā_w11_s12_y8 & $4.6^{\circ}$ & DLC16a_w8_s1_y-8 & $2.306 \mathrm{~m} / \mathrm{s}^{2}$ \\
\hline DLC11_w13_s18_y8 & $4.6^{\circ}$ & DLC16a_w8_s3_y0 & $2.301 \mathrm{~m} / \mathrm{s}^{2}$ \\
\hline \multicolumn{2}{|c|}{ Dynamic translational motion } & \multicolumn{2}{|c|}{ Mean translational motion } \\
\hline DLC16a_w8_s5_y8 & $11.4 \mathrm{~m}$ & DLC11_w11_s10_y0 & $20.9 \mathrm{~m}$ \\
\hline DLC11_w10_s3_y0 & $10.2 \mathrm{~m}$ & DLC13_w11_s10_y0 & $20.9 \mathrm{~m}$ \\
\hline DLC11_w13_s15_y0 & $10.1 \mathrm{~m}$ & DLC11_w11_s9_y0 & $20.6 \mathrm{~m}$ \\
\hline DLC16a_w8_s3_y0 & $10.1 \mathrm{~m}$ & DLC13_w11_s9_y0 & $20.6 \mathrm{~m}$ \\
\hline DLC11_w13_s16_y0 & $9.9 \mathrm{~m}$ & DLC16a_w11_s10_y0 & $20.4 \mathrm{~m}$ \\
\hline
\end{tabular}

It strikes that for both the total inclination angle and the horizontal nacelle acceleration, which are the two most important optimization criteria for the FOWT system, one and the same DLC simulation case, namely DLC16a_w11_s11_y8, appears among the five most critical DLCs. For the total inclination angle this DLC yields directly the maximum value, while for the horizontal nacelle acceleration it results in the second highest value, close to the maximum obtained with DLC 1.6a at cut-out wind speed. For the translational motions, however, DLC 1.6a at a lower wind speed yields the highest dynamic response, while DLC 1.1 yields the highest values for both the mean displacement and the total translational motion (maximum $28.0 \mathrm{~m}$ in DLC11_w11_s7_y-8). For DLC16a_w11_s11_y8 the maximum dynamic translational motion is $6.0 \mathrm{~m}$ (position 36 of all 54 DLC simulation cases) and the maximum mean translational motion is $20.2 \mathrm{~m}$ (position 9 of all 54 DLC simulation cases), while the total translational motion is the eighth largest with $25.9 \mathrm{~m}$. As for the translational motion the overall goal is to reduce the dynamic part without having a specific constraint on it and the highest mean translational motion is far below the specified constraint of $64.0 \mathrm{~m}$, but also as the greatest attention lies on the optimization criteria inclination and acceleration, DLC16a_w11_s11_y8 is directly selected as the critical DLC simulation settings to be used within the optimization iterations.

\subsection{Developments Throughout the Optimization}

Thus, the optimization is performed with the OC3 spar-buoy FOWT system model for DLC16a_w11_s11_y8, using the optimization settings as described in Section 4.3 and referring to the definitions in Chapter 2. A total of 2,011 simulations is executed, using 36 processors in parallel and taking in total eight days and five hours. Due to the internal approach of the optimizer (NSGAll) to manage the simulations of individuals within generations in parallel, all 36 individuals were created for a total of 52 generations - corresponding to the start generation 0 up to and including generation number 51 . Further individuals were generated up to generation number 57.

Figure 4 shows for all simulated individuals the development of their design variables (Figure 4(a)), as well as the resulting objective functions (Figure 4(b)) throughout the generations. In addition, the values of the original OC3 spar-buoy FOWT system design are added (red lines) for comparison purposes. From Figure 4(a) it can be seen that the optimizer first selects individuals from the entire value ranges of the design variables. The corresponding spread in the objective functions (Figure $4(\mathrm{~b})$ ) is obviously large for these first generations. However, throughout the optimization, having evaluated the objective functions and checked the constraints, more and more optimum design variables are selected by the optimizer and the objective functions improve. 

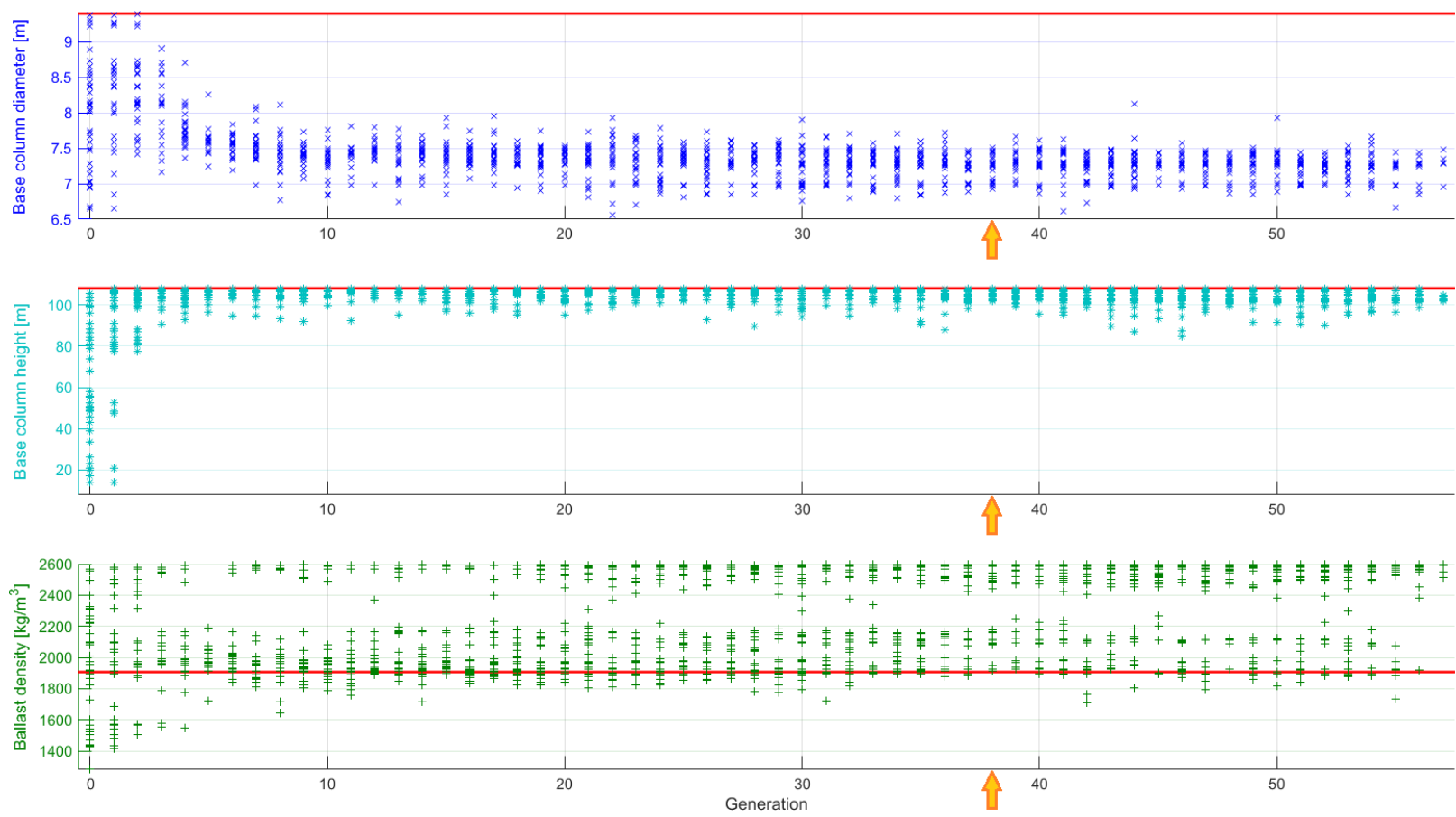

(a) Development of the design variables.
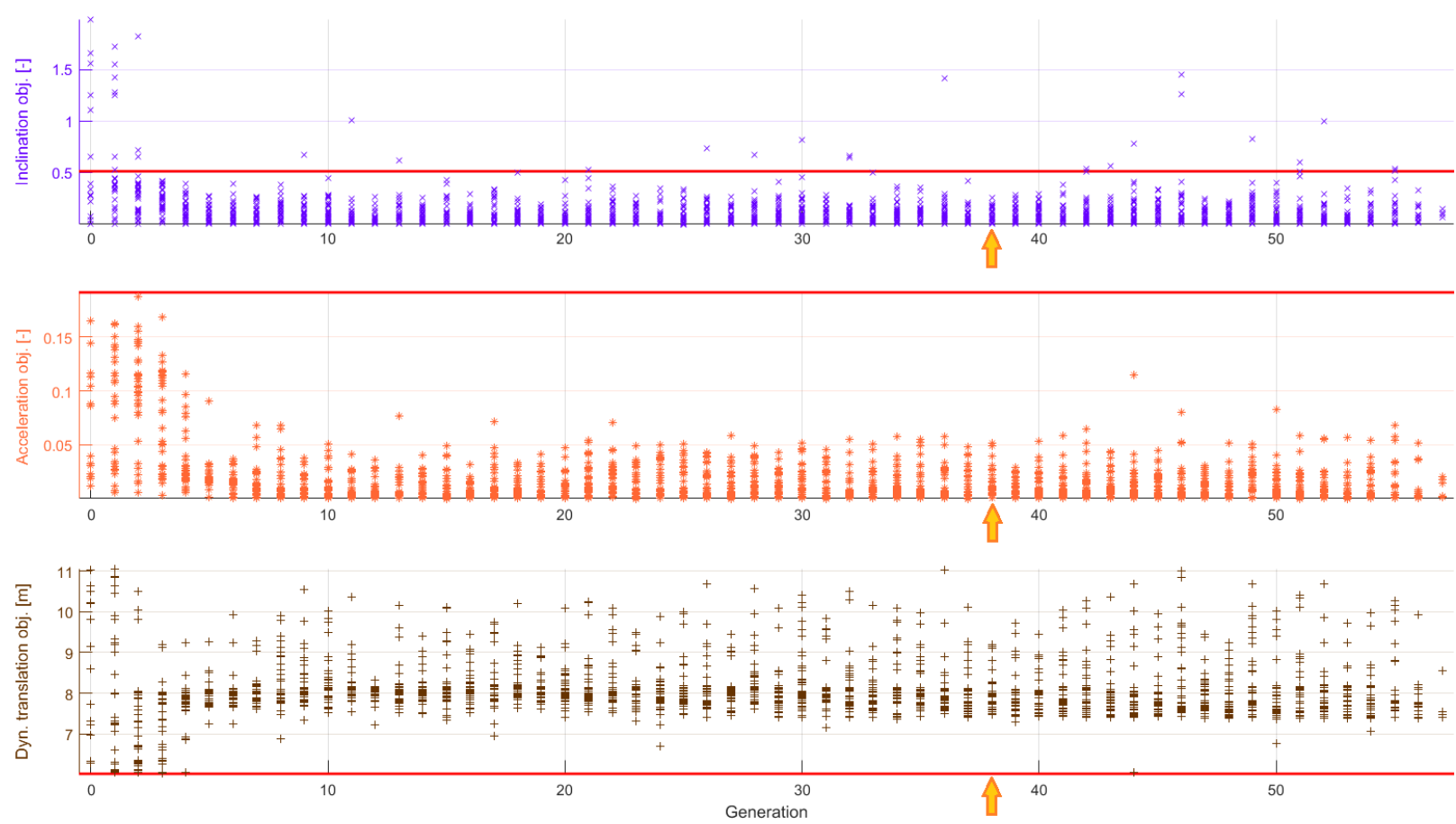

(b) Development of the objective functions.

Figure 4: Development of the 2,011 individuals throughout generation 0 up to generation 57 , red lines representing the original values of the OC3 FOWT system, arrows indicating the selected generation of convergence. 
Regarding the number of individuals (each represented by a marker) plotted in Figure 4 it has to be noted, that the incompleteness of generations above generation number 51 is clearly visible. Furthermore, in Figure 4(b), the objective functions of not all 36 individuals of generation 0 and generation 1 are plotted, as only the successful designs are evaluated with respect to the optimization objectives. However, due to the high flexibility of the selected optimizer NSGAll, already from the third generation (generation number 2 ) on all selected individuals complete the simulations without any failures.

\subsection{The Resulting Optimum Design}

Apart from the 29 individuals from the first two generations, which directly demonstrate imperfectness as their simulations fail, the remaining 1,982 individuals perform the simulations with success. From these it is now to select the one optimum individual.

\subsubsection{Selection Procedure of the Optimum Solution}

Before the optimum individual can be selected, first, the convergence of the optimization has to be checked, as already mentioned in Section 4.3. This is done mathematically by determining the spread of the design parameters - and for comparison reasons also the spread of the objective functions - within each generation. The calculations show that the optimizer converges to an optimum already within the first 10 generations, but then, as the stop criterion (the total number of simulations) is not yet reached, diverges again to try to find an even better optimum by increasing the spread within the design parameters again. However, as the optimizer had already found the optimum it converges back to this. This makes up the wavy pattern in the spread of the design variables and the objective functions, which can also directly be seen in Figure 4.

Based on these analyses, the overall minimum spread within the design variables is obtained in generation number 38 (with some other local minima in already earlier generations from generation 5 on), proving again that the selected total number of simulations was sufficiently high for obtaining convergence within the optimization. Furthermore, Figure 5 shows 3D and 2D plots for both the development of the design variables, as well as the objective functions from generation 0 up to the selected generation 38. Here (Figure 5(a)), it can clearly be seen that the individuals of generation 0 fill out the entire space of the allowable values for the design variables, while the individuals of generation 38 troop together around the optimum. With respect to the objective functions, the 3D plot and even more clearly the 2D plots in Figure 5(b) show rather how the developing individuals form a Pareto front, on which most of the individuals of generation 38 are in the corner of optimum performance, indicated by low values for the objective functions.

Thus, from this selected generation of convergence (pointed out by arrows in Figure 4) now the final optimum design solution has to be chosen. To do so, first, the prescribed constrains are checked and not complying individuals are rejected. Then, the optimum value for each objective function is determined from the complying individuals within generation 38. These three values together are taken as the utopia point, which hence represents the ideal performance. Then, for each individual within generation 38 , which fulfills the constraints, its distance to the utopia point is identified by determining from the differences between the inclination, acceleration, and normalized dynamic translational motion objective function values and the corresponding utopia values the overall distance by means of the root of the sum of the differences squared. As the inclination and acceleration objective functions have already been normalized with respect to their target values, the absolute difference is computed for these two criteria. However, for the dynamic translational motion, the difference between achieved value and utopia value is normalized with respect to the value of the utopia, to allow for equally weighted consideration of the three optimization criteria. Following this approach, individual number 18 within generation 38 is obtained as the optimum design with the minimum distance to the utopia point. The properties of this optimum individual are presented in the following.

\subsubsection{The Optimized Spar-Buoy Floater}

The shape of the optimum spar-buoy floater is drawn schematically in Figure 6 and compared to the original spar-buoy floater design, as well as a few exemplary designs of individuals in start generation 0 , showing the 

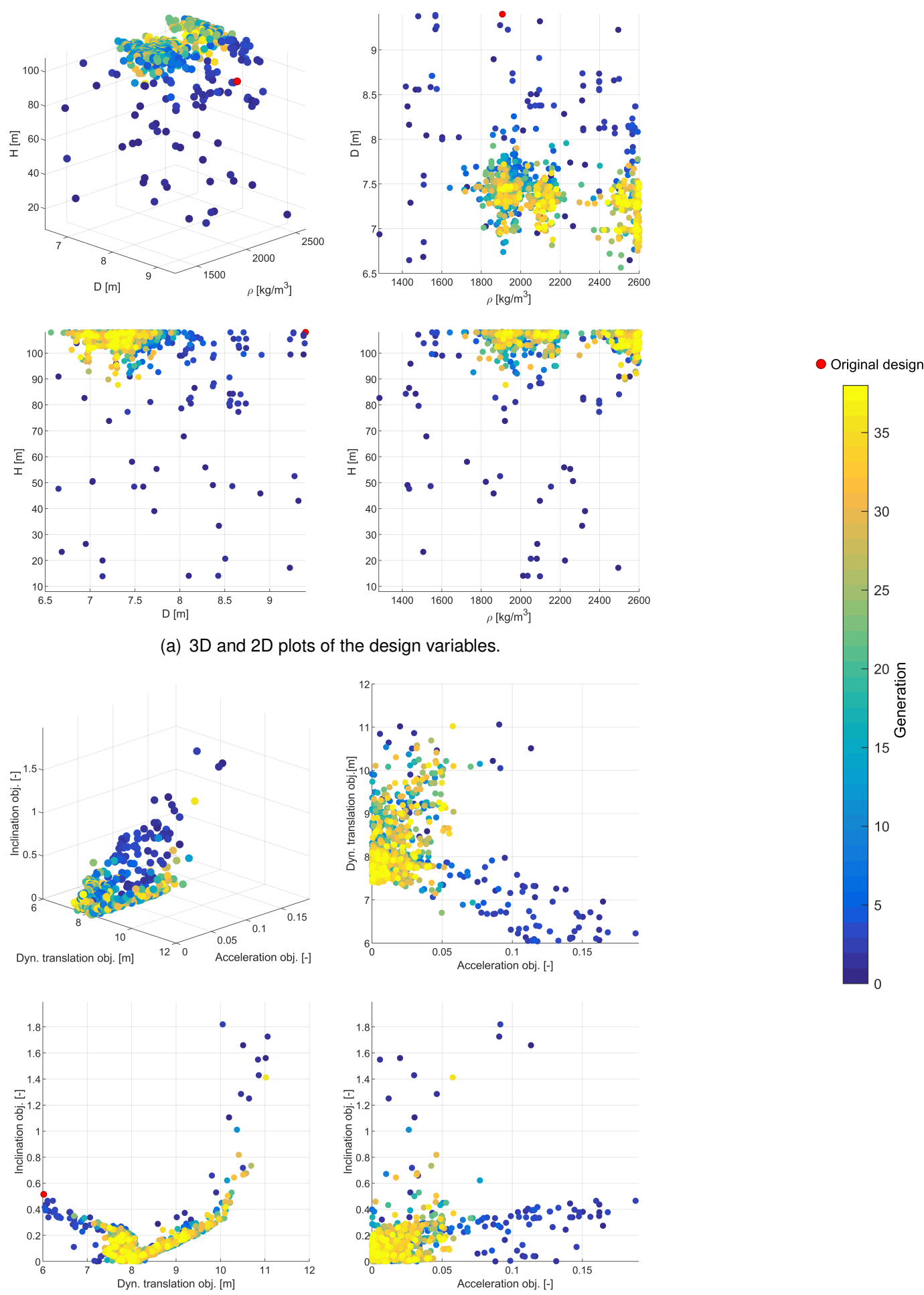

(b) $3 \mathrm{D}$ and $2 \mathrm{D}$ plots of the objective functions.

Figure 5: Development of the individuals throughout generation 0 up to the selected generation 38 of convergence. 
exploited value ranges of the design variables. The specific numbers for the values of the design variables of the determined optimum floating spar-buoy structure are presented in Table 6. As it can be seen, when comparing the values to the original OC3 spar-buoy floater design, the outer dimensions could be reduced, what was aimed for within the optimization and realized through the specified allowable value ranges for the design variables; however, this was only possible as the original OC3 spar-buoy floater design was - as already indicated in Chapter 1 and Section 2.1 - highly over-dimensioned for safety reasons, which can as well be seen in the very limited system response, as presented in Table 7 and discussed in more detail in Subsection 5.3.3. Furthermore, based on the additionally presented values for the structural mass of the spar-buoy, as well as for the ballast mass, a significant reduction in the overall mass of the floating platform is observed. By means of the optimized floater design, the ballast mass is more than halved and the required structural mass is reduced by almost $24 \%$, on which basis it can be expected to obtain also a drop in the system costs, which was as well an overall objective within this study.

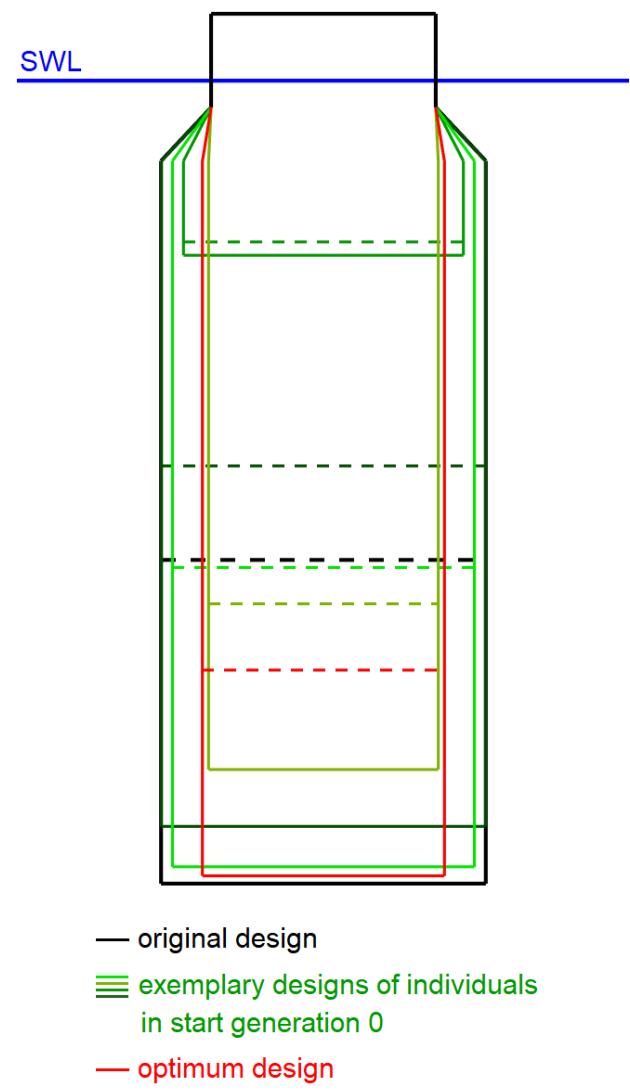

Figure 6: Design shapes in comparison, dashed lines indicating the ballast height.
Table 6: Design variables of the optimum design in comparison with the specified value ranges and original values.

\begin{tabular}{lccc}
\hline Variable & Value & $\begin{array}{c}\text { Allowable } \\
\text { value range }\end{array}$ & $\begin{array}{c}\text { Original } \\
\text { value }\end{array}$ \\
\hline Base column diameter $[\mathrm{m}]$ & 7.0 & $6.5-9.4$ & 9.4 \\
Base column height $[\mathrm{m}]$ & 106.8 & $8.0-108.0$ & 108.0 \\
Ballast density $\left[\mathrm{kg} / \mathrm{m}^{3}\right]$ & 2,584 & $1,281-2,600$ & 1,907 \\
\hline Ballast height $[\mathrm{m}]$ & 30.8 & - & 48.4 \\
\hline Structural mass $\left[10^{6} \mathrm{~kg}\right]$ & 0.877 & - & 1.150 \\
Ballast mass $\left[10^{6} \mathrm{~kg}\right]$ & 3.007 & - & 6.316 \\
\hline
\end{tabular}

Table 7: Optimization criteria of the optimum design in comparison with the targets, constraints, and original values.

\begin{tabular}{lcccc}
\hline Objective & $\begin{array}{c}\text { Value } \\
(\mathbf{m a x})\end{array}$ & $\begin{array}{c}\text { Target } \\
\text { value }\end{array}$ & $\begin{array}{c}\text { Con- } \\
\text { straint }\end{array}$ & $\begin{array}{c}\text { Original } \\
\text { value (max) }\end{array}$ \\
\hline $\begin{array}{l}\text { Total inclination } \\
\text { angle }\left[^{\circ} \text { ] }\right.\end{array}$ & 9.9 & 10.0 & $\leq 10.0$ & 4.9 \\
$\begin{array}{l}\text { Dynamic transla- } \\
\text { tional motion [m] }\end{array}$ & 7.7 & min. & $\geq 0.0$ & 6.0 \\
$\begin{array}{l}\text { Horizontal nacelle } \\
\text { acceleration [m/s }\end{array}$ & 1.910 & 1.962 & $\leq 1.962$ & 2.338 \\
\hline $\begin{array}{l}\text { Mean transla- } \\
\text { tional motion [m] }\end{array}$ & 26.7 & - & $\leq 64.0$ & 20.2 \\
\hline
\end{tabular}

\subsubsection{Performance Checks}

As already indicated in Subsection 5.3.1, the constraints are checked again before selecting the optimum individual. Table 6 shows that the chosen values for the design variables fall within the specified allowable value ranges. In addition to the design variables, also the optimization criteria are approved. Table 7 presents the achieved maximum values for the global limit states, as well as the additional constrained mean translational motion parameter. It can be seen that all parameters comply with the defined constraints. Furthermore, the targets for inclination and acceleration are very closely approached. Comparing the results with the maximum values obtained with the original OC3 spar-buoy FOWT system, it can be observed, at first, that not all constraints are 
initially fulfilled: the maximum achieved horizontal nacelle acceleration of the original OC3 floating spar-buoy system exceeds with $2.338 \mathrm{~m} / \mathrm{s}^{2}$ the specified upper limit of $1.962 \mathrm{~m} / \mathrm{s}^{2}$; however, the value still lies below $0.3 \mathrm{~g}$, which can as well be found in some literature as operational limit [38,42]. Furthermore, it becomes apparent that both inclination angle and nacelle acceleration are significantly improved with respect to the specified objectives, meaning that the horizontal nacelle acceleration is now within the specified limit, but very close to it, and the maximum total system inclination angle is significantly enlarged - compared to the original maximum angle of $4.9^{\circ}$-, but as well still below the specified operational value of $10.0^{\circ}$. This is closely related to the reduced outer dimensions, as already mentioned and presented in Table 6. The translational motions of the optimum design are slightly larger than with the original design; however, the increase in the dynamic motion is minor and the constraint for the mean displacement is still fulfilled with a large clearance to the limit value.

The final check goes to the critical DLC, as already examined and mentioned in Section 4.1 in step 5. Thus, the 54 DLC simulation cases, as specified in Section 5.1, are run with the same simulation settings but now with the optimized spar-buoy floater design found beforehand. The evaluation of the time series reveals that the selected critical DLC16a_w11_s11_y8 yields the highest horizontal nacelle acceleration. However, for the other optimization objectives DLC16a_w11_s11_y8 is not the most critical DLC simulation case. Table 8 summarizes the results of the review of the critical DLC. For the dynamic translational motion, DLC16a_w11_s11_y8 was already not the most critical DLC simulation case with the original OC3 spar-buoy FOWT system and just on position 36 in the ranking; whereas with the optimized spar-buoy design it moved up to position 32 . A similar change is seen for the constrained mean translational motion parameter. Furthermore, the value obtained with the most critical DLC is only marginally larger than the maximum mean translational motion in DLC16a_w11_s11_y8 and still significantly below the set constraint.

Table 8: Values for the optimization objectives and constrained parameters from DLC16a_w11_s11_y8 and the most critical DLC, original and optimized spar-buoy design in comparison.

\begin{tabular}{llcccc}
\hline & & \multicolumn{2}{c}{ DLC16a_w11_s11_y8 } & \multicolumn{2}{c}{ Most critical DLC } \\
& & Position & Value & Value & DLC simulation case \\
\hline Total inclination angle & Original & 1 & $4.9^{\circ}$ & $4.9^{\circ}$ & DLC16a_w11_s11_y8 \\
& Optimized & 9 & $9.9^{\circ}$ & $11.5^{\circ}$ & DLC11_w13_s16_y0 \\
Horizontal nacelle acceleration & Original & 2 & $2.338 \mathrm{~m} / \mathrm{s}^{2}$ & $2.351 \mathrm{~m} / \mathrm{s}^{2}$ & DLC16a_w25_s16_y0 \\
& Optimized & 1 & $1.910 \mathrm{~m} / \mathrm{s}^{2}$ & $1.910 \mathrm{~m} / \mathrm{s}^{2}$ & DLC16a_w11_s11_y8 \\
Dynamic translational motion & Original & 36 & $6.0 \mathrm{~m}$ & $11.4 \mathrm{~m}$ & DLC16a_w8_s5_y8 \\
& Optimized & 32 & $7.7 \mathrm{~m}$ & $13.4 \mathrm{~m}$ & DLC16a_w8_s5_y8 \\
\hline Mean translational & Original & 9 & $20.2 \mathrm{~m}$ & $20.9 \mathrm{~m}$ & DLC11_w11_s10_y0 \\
motion & Optimized & 6 & $26.7 \mathrm{~m}$ & $27.3 \mathrm{~m}$ & DLC16a_w11_s10_y0 \\
\hline
\end{tabular}

Thus, the only relevant difference between the original and optimized design, with respect to the critical DLC simulation case, is the maximum value for the total inclination angle. The selected critical DLC is for the optimized design (with an achieved value of $9.9^{\circ}$ ) just on position 9 in the ranking and the most critical DLC yields an inclination angle of $11.5^{\circ}$, which exceeds the prescribed operating limit of $10^{\circ}$. The analysis shows that six DLC simulation cases yield maximum inclination angles higher than $10^{\circ}$. Within this study, however, this is accepted and no new critical DLC is selected, as spar-buoy FOWT systems should even in a damaged condition persist a maximum inclination angle of $17^{\circ}$ [50]. This means, that with the optimized spar-buoy FOWT it might happen that - in six out of 54 environmental conditions - the wind turbine has to stop operation at certain times, but the system stability would never become critical. In the following Chapter 6 some further strategies are proposed. 


\section{Discussion}

First of all, it has to be emphasized that the presented design optimization of the OC3 spar-buoy FOWT system is kept deliberately simple and focuses mainly on the global system performance, as well as on the reduction of the outer dimensions. However, with the selected design variables (spar-buoy diameter and length, as well as the ballast density), one of the optimization objectives, namely the dynamic translational motion, as well as the constrained mean translational motion, can only be marginally influenced, which is reflected by the increased translational motions of the optimized design compared to the original design, as presented in Tables 7 and 8 . Even though the wave drift forces - contributing to the surge motion - depend on the frontal area of the spar-buoy and, hence, its outer dimensions which are selected as design variables, the decisive influencing factor on the surge motion of a spar-buoy floating wind turbine system is the station-keeping system. Thus, mooring system parameters would have to be added as design variables to directly address the translational motion objective within the optimization. Furthermore, the optimized floating spar-buoy wind turbine system - with reduced floater outer dimensions and more critical, but still safe system inclination - will experience a larger bending moment at the tower base, as well as increased loads in the yaw bearing and at the blade roots, suffer losses in the power output, and impair the performance of the generator speed control. Hence, further local and more detailed criteria - such as (local) structural integrity checks, load and fatigue analyses, or even reliability aspects - as well as additional design variables (for the structure, but also for the mooring system or the turbine control) would have to be incorporated in the presented optimization approach for a high-quality and fully adequate design analysis and optimization.

With respect to the presented optimization approach and demonstrated application example, a sensitive issue is the critical DLC, which is used for the simulations during the optimization. This methodology is on the one hand very reasonable, as from a computational (and cost) point of view running the entire DLC set from the standard with each individual within the optimization iterations would not be advisable; however, on the other hand, when using only one DLC simulation case within the optimization procedure, this DLC has to be selected very carefully. Hence, in Section 4.1 an approach for selecting and approving this one critical DLC is suggested. In the presented application example it turns out that easily the most critical DLC can shift during the optimization, which emphasizes again the relevance of the check at the end and potential adjustments. In the design optimization of the OC3 spar-buoy, no amendments to the initially selected critical DLC are made, as the target and limit values for the two most important optimization objectives are set with allowance for some tolerance above:

- For the total inclination angle, the maximum operational value of $10^{\circ}$ is selected, meaning that the FOWT system remains still stable at higher values but the turbine might has to stop operation. This is accepted for the six out of 54 DLC simulation cases, in which the operational limit is slightly exceeded.

- For the horizontal nacelle acceleration, the more conservative value of maximum $0.2 \mathrm{~g}$ is selected. This leaves some safety margin for higher values in case that the ranking of criticality of the DLCs changes during the optimization, as even up to $0.3 \mathrm{~g}$ is mentioned as common operational limit $[38,42]$.

Apart from the proposed methodology in Section 4.1, implying re-evaluation and modification of the selected critical DLC, another possible approach is to apply some safety factors to the overall limits for the optimization objectives, as it is indirectly done in the presented application example in this study.

Another aspect of high importance is the optimizer and the convergence of the optimization. This is checked and approved within this study; however, the most appropriate optimizer, as well as its rate of convergence depend on the explicit application example (both the simulated system and the specified optimization problem). Thus, for any other and further studies and optimization tasks, it is highly recommended to perform sensitivity studies on the selection of the suitable optimizer and afterwards as well on approving its convergence within the optimization procedure.

Finally, the obtained optimum floater design needs to be discussed. Due to the complexity of FOWT systems and the multi-objective optimization problem, it cannot directly be said how the optimum design will look 
like, especially as the multi-objective optimization yields actually a set of optimal designs (the Pareto front), as presented in Subsection 5.3.1. However, based on the prime principle laws of FOWT system responses, a first estimate on the direction, in which the optimization will go, as well as on the expected values compared to the initial system design can be given. Thus, using the static analysis of the global motion response of a floating system, the highest inclination angle $(\theta)$ is expected at rated wind speed, yielding the highest thrust force and corresponding overturning moment $(M)$, as already indicated in the pre-selection of critical DLCs (Section 4.1). The static relation between $\theta$ and $M$ is given by means of the system stiffness $C$, as expressed in Equation 22 .

$$
\theta=\frac{M}{C}
$$

Due to the geometry of the spar-buoy floater, the system stiffness in the roll and pitch degrees of freedom are the same and follow Equation 23, with the density of water $\rho$, the gravitational acceleration $g$, the diameter $D$ of the spar at the water-plane area, the total mass $m$ of the entire FOWT system, as well as the vertical positions of the center of buoyancy and center of mass $\left(z_{\mathrm{B}}\right.$ and $z_{\mathrm{G}}$, respectively), having $z=0$ at and $z<0$ below SWL.

$$
C=\rho g \frac{\pi}{64} D^{4}+m g\left(z_{\mathrm{B}}-z_{\mathrm{G}}\right)
$$

Comparing the original maximum total inclination angle $\left(4.9^{\circ}\right)$ with the target value $\left(10.0^{\circ}\right)$, it is obvious that $\theta$ has to be increased within the optimization iterations. Due to the fact that the environmental conditions are unchanged during the optimization, the loading on the turbine can be considered as constant, neglecting an influence on the final overturning moment due to a changed point of rotation because of altered centers of buoyancy and mass. Thus, to enlarge $\theta$, the system stiffness $C$ has to be reduced. However, as the spar diameter at SWL (the upper base diameter) is not modifiable, a smaller stiffness can only be obtained by a reduced distance between the centers of buoyancy and mass. This initial estimation of changes between the obtained optimum and the original floater design is examined. The specific numbers for the centers of buoyancy and mass, as well as their vertical distance to each other, determined for both the original and the obtained optimum FOWT system (Table 9), substantiate the approximate estimations and the reasonability of the optimum floater design solution obtained with the presented optimization approach.

Table 9: Comparison of the centers of buoyancy and mass of the original and optimum FOWT systems for interpreting the results obtained with the optimization approach.

\begin{tabular}{lcc}
\hline Parameter & Original FOWT system & Optimum FOWT system \\
\hline$z_{\mathrm{B}}[\mathrm{m}]$ & -62.1 & -59.9 \\
$z_{\mathrm{G}}[\mathrm{m}]$ & -78.0 & -70.7 \\
$z_{\mathrm{B}}-z_{\mathrm{G}}[\mathrm{m}]$ & 15.9 & 10.8 \\
\hline
\end{tabular}

\section{Conclusion}

In this paper, a design optimization approach is presented and applied to the OC3 spar-buoy FOWT system. The study focuses on global limit states and aims for cost reduction by means of reducing the outer dimensions of the floater, as well as using cheap and common ballast materials. This work covers the entire methodology for a design optimization task: 1) starting with the reference system and its implementation in the MoWiT library for being simulated in Dymola; 2 ) including the substantiated selection and specification of the design variables and global limit states; 3) processing these for the formal description of the optimization problem; 4) continuing with the definition of one critical simulation case, which is used within the optimization iterations; 5) proceeding to the integration and utilization of the Python-Modelica framework for automated simulation and optimization; 6) followed by the profound choice of the optimizer and corresponding settings, as well as its approval of convergence; 7) and finishing off with the final selection approach of the optimum and its evaluation. Keeping the scope of this 
study in mind, the presented optimization approach and demonstrated application example show a successful design optimization of a floating spar-buoy wind turbine system by means of global limit states definitions and utilization of a Python-Modelcia framework. The outer dimensions (spar-buoy base column diameter and height) can be reduced by more than $25 \%$ and $1 \%$, respectively, which results in almost $24 \%$ reduction in structural mass and related material cost. By using a more than $35 \%$ denser ballast, but still only requiring less than half of the original ballast mass, a sufficient deep center of mass can be obtained to meet the stability and dynamic performance requirements. These results and the presented methodologies serve as basis for further in depth and more sophisticated application of the design optimization approach, including local criteria, integrity checks, fatigue analyses, as well as reliability aspects.

\section{Acknowledgements}

This work was partially supported by grant EP/L016303/1 for Cranfield University, University of Oxford and University of Strathclyde, Centre for Doctoral Training in Renewable Energy Marine Structures - REMS (http://www.remscdt.ac.uk/) from the UK Engineering and Physical Sciences Research Council (EPSRC) and the German Fraunhofer Institute for Wind Energy Systems (Fraunhofer IWES).

\section{References}

[1] E. Mast, R. Rawlinson, C. Sixtensson, TKI Wind op Zee: Potential of floating offshore wind: Market study floating wind in the Netherlands, RVO (Netherlands Enterprise Agency), 2015.

[2] M. T. J. Hall, Mooring Line Modelling and Design Optimization of Floating Offshore Wind Turbines, Master's thesis, University of Victoria, 2013.

[3] M. Hall, B. Buckham, C. Crawford, Hydrodynamics-based floating wind turbine support platform optimization: A basis function approach, Renewable Energy 66 (2014) 559-569.

[4] M. Karimi, M. Hall, B. Buckham, C. Crawford, A multi-objective design optimization approach for floating offshore wind turbine support structures, Journal of Ocean Engineering and Marine Energy 3 (2017) 69-87.

[5] F. Lemmer, K. Müller, W. Yu, D. Schlipf, P. W. Cheng, Optimization of Floating Offshore Wind Turbine Platforms With a Self-Tuning Controller, in: ASME 2017 36th International Conference on Ocean, Offshore and Arctic Engineering: June 25-30, 2017, Trondheim, Norway, American Society of Mechanical Engineers, New York, N.Y., 2017. doi:10.1115/OMAE2017-62038.

[6] F. Sandner, D. Schlipf, D. Matha, P. W. Cheng, Integrated Optimization of Floating Wind Turbine Systems, in: ASME 33rd International Conference on Ocean, Offshore and Arctic Engineering: June 8-13, 2014, San Francisco, California, USA, American Society of Mechanical Engineers, New York, N.Y., 2014. doi:10.1115/OMAE2014-24244.

[7] I. Fylling, P. A. Berthelsen, WINDOPT: An Optimization Tool for Floating Support Structures for Deep Water Wind Turbines, in: ASME 2011 30th International Conference on Ocean, Offshore and Arctic Engineering: June 19-24, 2011, Rotterdam, The Netherlands, ASME, 2011, pp. 767-776. doi:10.1115/OMAE2011-49985.

[8] G. F. Clauss, L. Birk, Hydrodynamic shape optimization of large offshore structures, Applied Ocean Research 18 (1996) $157-171$.

[9] A. Härer, Optimierung von Windenergieanlagen-Komponenten in Mehrkörpersimulationen zur Kosten- und Lastreduktion, Diploma, Stiftungslehrstuhl Windenergie Universität Stuttgart, 2013.

[10] T. Gentils, L. Wang, A. Kolios, Integrated structural optimisation of offshore wind turbine support structures based on finite element analysis and genetic algorithm, Applied Energy 199 (2017) 187-204.

[11] M. Muskulus, S. Schafhirt, Design Optimization of Wind Turbine Support Structures - A Review, Journal of Ocean and Wind Energy 1 (2014) 12-22.

[12] K.-H. Chew, K. Tai, E. Ng, M. Muskulus, Analytical gradient-based optimization of offshore wind turbine substructures under fatigue and extreme loads, Marine Structures 47 (2016) 23-41.

[13] L. E. S. Stieng, M. Muskulus, Reliability-based design optimization of offshore wind turbine support structures using analytical sensitivities and factorized uncertainty modeling, Wind Energy Science Discussions, in review (2019).

[14] T. Ashuri, M. B. Zaaijer, J. Martins, G. van Bussel, G. van Kuik, Multidisciplinary design optimization of offshore wind turbines for minimum levelized cost of energy, Renewable Energy 68 (2014) 893-905.

[15] L. Wang, A. Kolios, M. M. Luengo, X. Liu, Structural optimisation of wind turbine towers based on finite element analysis and genetic algorithm, Wind Energy Science Discussions (2016) 1-26.

[16] V. Mytilinou, A. J. Kolios, Techno-economic optimisation of offshore wind farms based on life cycle cost analysis on the UK, Renewable Energy 132 (2019) 439-454.

[17] V. Mytilinou, E. Lozano-Minguez, A. Kolios, A Framework for the Selection of Optimum Offshore Wind Farm Locations for Deployment, Energies 11 (2018) 1855. 
[18] V. Mytilinou, A. J. Kolios, A multi-objective optimisation approach applied to offshore wind farm location selection, Journal of Ocean Engineering and Marine Energy 3 (2017) 265-284.

[19] P. Hou, J. Zhu, K. MA, G. YANG, W. HU, Z. CHEN, A review of offshore wind farm layout optimization and electrical system design methods, Journal of Modern Power Systems and Clean Energy 7 (2019) 975-986.

[20] J. Herbert-Acero, O. Probst, P.-E. Réthoré, G. Larsen, K. Castillo-Villar, A Review of Methodological Approaches for the Design and Optimization of Wind Farms, Energies 7 (2014) 6930-7016.

[21] P. S. Valverde, Sarmento, António J. N. A., M. Alves, Offshore Wind Farm Layout Optimization - State of the Art, Journal of Ocean and Wind Energy 1 (2014) 23-29.

[22] F. Lemmer, K. Müller, W. Yu, R. F. Guzman, M. Kretschmer, Qualification of innovative floating substructures for 10MW wind turbines and water depths greater than 50m: Deliverable D4.3 Optimization framework and methodology for optimized floater design, 2016.

[23] M. Leimeister, Python-Modelica Framework for Automated Simulation and Optimization, in: Proceedings of the 13th International Modelica Conference, Regensburg, Germany, March 4-6, 2019, Linköping Electronic Conference Proceedings, Linköping University Electronic Press, 2019, pp. 51-58. doi:10.3384/ecp1915751.

[24] M. Leimeister, A. Kolios, M. Collu, P. Thomas, Development of a Framework for Wind Turbine Design and Optimization: (to be published) (2019).

[25] M. Leimeister, P. Thomas, The OneWind Modelica Library for Floating Offshore Wind Turbine Simulations with Flexible Structures, in: Proceedings of the 12th International Modelica Conference, Prague, Czech Republic, May 15-17, 2017, Linköping Electronic Conference Proceedings, Linköping University Electronic Press, 2017, pp. 633-642. doi:10.3384/ecp17132633.

[26] P. Thomas, X. Gu, R. Samlaus, C. Hillmann, U. Wihlfahrt, The OneWind Modelica Library for Wind Turbine Simulation with Flexible Structure - Modal Reduction Method in Modelica, in: Proceedings of the 10th International Modelica Conference, March 1012, 2014, Lund, Sweden, Linköping Electronic Conference Proceedings, Linköping University Electronic Press, 2014, pp. 939-948. doi:10.3384/ECP14096939.

[27] M. Strobel, F. Vorpahl, C. Hillmann, X. Gu, A. Zuga, U. Wihlfahrt, The OnWind Modelica Library for Offshore Wind Turbines - Implementation and first results, in: Proceedings from the 8th International Modelica Conference, Technical Univeristy, Dresden, Germany, Linköping Electronic Conference Proceedings, Linköping University Electronic Press, 2011, pp. 603-609. doi:10.3384/ecp11063603.

[28] M. Leimeister, A. Kolios, M. Collu, P. Thomas, Development and Verification of an Aero-Hydro-Servo-Elastic Coupled Model of Dynamics for FOWT, Based on the MoWiT Library: (to be published), Renewable Energy (2019).

[29] M. Leimeister, A. Kolios, M. Collu, P. Thomas, Larger MW-Class Floater Designs Without Upscaling? - A Direct Optimization Approach, in: Proceedings of the ASME 2019 38th International Conference on Ocean, Offshore and Arctic Engineering OMAE 2019, ASME, 2019, pp. OMAE2019-95210.

[30] M. Leimeister, A. Kolios, M. Collu, Critical review of floating support structures for offshore wind farm deployment, Journal of Physics: Conference Series 1104 (2018) 012007.

[31] J. Jonkman, Definition of the Floating System for Phase IV of OC3, NREL/TP 500-47535, National Renewable Energy Laboratory, Golden, Colorado, 2010. doi:10.2172/979456.

[32] J. Jonkman, S. Butterfield, W. Musial, G. Scott, Definition of a 5-MW Reference Wind Turbine for Offshore System Development, NREL/TP 500-38060, National Renewable Energy Laboratory, Golden, Colorado, 2009. doi:10.2172/947422.

[33] C. Ng, L. Ran (Eds.), Offshore Wind Farms: Technologies, Design and Operation, Woodhead Publishing series in energy, Woodhead Publishing, Oxford, 2016.

[34] A. Robertson, J. Jonkman, M. Masciola, H. Song, A. Goupee, A. Coulling, C. Luan, Definition of the Semisubmersible Floating System for Phase II of OC4, NREL/TP-5000-60601, National Renewable Energy Laboratory, Golden, Colorado, 2014.

[35] The Engineering ToolBox, Densities of Common Materials, 2017. URL: http://www.engineeringtoolbox.com/density-materialsd_1652.html.

[36] R. C. Dorf, The engineering handbook, CRC Press, Boca Raton, Florida, 1996.

[37] Arbeitsgemeinschaft der Bau-Berufsgenossenschaften, Gewichtstabellen für Turmdrehkranführer, 2000. URL: http://www.bgbaumedien.de/bau/bau507/1.htm.

[38] F. Huijs, J. Mikx, F. Savenije, E.-J. de Ridder, Integrated design of floater, mooring and control system for a semi-submersible floating wind turbine, in: Proceedings of the EWEA Offshore 2013, Frankfurt, Germany, 2013.

[39] A. Kolios, M. Borg, D. Hanak, Reliability analysis of complex limit states of floating wind turbines, Journal of Energy Challenges and Mechanics 2 (2015) 6-9.

[40] G. Katsouris, A. Marina, Cost Modelling of Floating Wind Farms, ECN-E-15-078, 2016.

[41] E. E. Bachynski, T. Moan, Design considerations for tension leg platform wind turbines, Marine Structures 29 (2012) 89-114.

[42] A. R. Nejad, E. E. Bachynski, T. Moan, On Tower Top Axial Acceleration and Drivetrain Responses in a Spar-Type Floating Wind Turbine, in: ASME 2017 36th International Conference on Ocean, Offshore and Arctic Engineering: June 25-30, 2017, Trondheim, Norway, American Society of Mechanical Engineers, New York, N.Y., 2017, p. V009T12A009. doi:10.1115/OMAE2017-62314.

[43] K. Suzuki, H. Yamaguchi, M. Akase, A. Imakita, T. Ishihara, Y. Fukumoto, T. Oyama, Initial Design of Tension Leg Platform for Offshore Wind Farm, Journal of Fluid Science and Technology 6 (2011) 372-381.

[44] International Electrotechnical Commission, Wind turbines - Part 3: Design requirements for offshore wind turbines, IEC 61400-3, 2009.

[45] E. E. Bachynski, M. Etemaddar, M. I. Kvittem, C. Luan, T. Moan, Dynamic Analysis of Floating Wind Turbines During Pitch Actuator Fault, Grid Loss, and Shutdown, Energy Procedia 35 (2013) 210-222.

[46] D. Matha, F. Sandner, D. Schlipf, Efficient critical design load case identification for floating offshore wind turbines with a reduced nonlinear model, Journal of Physics: Conference Series 555 (2014) 012069.

[47] A. Krieger, G. K. V. Ramachandran, L. Vita, P. G. Alonso, G. G. Almería, J. Berque, G. Aguirre, Deliverable D7.2 Design Basis: LIFES50+, 
2015.

[48] International Electrotechnical Commission, Wind turbines - Part 1: Design requirements, IEC 61400-1, 2005.

[49] H. Bredmose, S. E. Larsen, D. Matha, A. Rettenmeier, E. Marino, L. Saettran, D2.4: Collation of offshore wind-wave dynamics: Revision: 02, MARINET, 2012.

[50] DNV GL AS, Floating wind turbine structures, DNVGL-ST-0119, 2018. 